\title{
Modeling transverse heating and outflow of ionospheric ions from the dayside cusp/cleft. 2 Applications
}

\author{
M. Bouhram ${ }^{1, *}$, M. Malingre ${ }^{1}$, J. R. Jasperse ${ }^{2}$, N. Dubouloz ${ }^{3}$, and J.-A. Sauvaud ${ }^{4}$ \\ ${ }^{1}$ CETP-CNRS, 4 Avenue de Neptune, 94107 Saint-Maur Cedex, France \\ ${ }^{2}$ Air Force research laboratory, Hanscom AFB, MA 01731-3010, USA \\ ${ }^{3}$ PCE-CNRS, 45071 Orleans Cedex 02, France \\ ${ }^{4}$ CESR-CNRS, BP-4346, 31028 Toulouse Cedex 04, France \\ *now at: Max-Planck-Institut für Extraterrestrische Physik, 85741 Garching, Germany
}

Received: 15 October 2002 - Revised: 17 February 2003 - Accepted: 27 February 2003

\begin{abstract}
In this paper, we consider major ion energization mechanisms in the dayside cusp/cleft region. This includes transverse ion heating by ion cyclotron resonance (ICR), ion energization through structures of field-aligned electric potential drops, and transverse heating by lower hybrid (LH) waves. First, we present and discuss three typical cusp/cleft crossings associated with one of the first two mechanisms mentioned above. Then, we develop a procedure for finding the altitude dependence of ICR heating for any data set in the high-altitude cusp/cleft under the absence of field-aligned potential drops. This has been accomplished using a large set of numerical simulations from a two-dimensional, steadystate, Monte Carlo, trajectory-based code, as discussed in detail in the first companion paper (Bouhram et al., 2003). The procedure is applied and tested successfully for the first two events, by using patterns of ion moments along the satellite track as constraints. Then, we present a statistical study that uses $25 \mathrm{cusp} / \mathrm{cleft}$ crossings associated with steady IMF conditions, where ICR heating is expected to occur alone. It is pointed out that the ICR heating increases gradually versus geocentric distance as $s^{3.3 \pm 1.8}$. The inferred values of the wave power and the spectral index associated with the component responsible for ICR heating are lower than those characterizing the broad-band, extremely low-frequency (BBELF) turbulence usually observed in the cusp/cleft. This strengthens the idea that more than one wave-mode is contained in the BBELF turbulence, and only a small fraction of the observed turbulence is responsible for ICR heating. Then, we study the occurrence versus magnetic local time (MLT) of field-aligned potential drops. According to previous statistical studies, such structures are not common in the cusp and tend to be associated with the cleft region. We also discuss the effects of LH heating in the cusp on the observed ion distributions. However, this mechanism turns out to be of less importance than ICR heating.
\end{abstract}

Key words. Magnetospheric physics (Auroral phenomena)

Correspondence to: M. Bouhram (bouhram@mpe.mpg.de)
- Space plasma physics (charged particle motion and acceleration; wave-particle interactions)

\section{Introduction}

The energization and outflow of ionospheric ions at auroral latitudes has been an area of active research over the past three decades, since it was first observed by Shelley et al. (1972). Some recent reviews can be found in André and Yau (1997) and Moore et al. (1999).

The dayside cusp/cleft region has been identified as the major source of ionospheric ions for the magnetosphere (Lockwood et al., 1985). Inside these regions, the energetic, or non-thermal ion outflow is classified into beams and conics. Beams have a strongly field-aligned flux, and tend to be associated with acceleration through structures of fieldaligned potential drops. Conics have a peak flux in a direction oblique to the upward direction and are caused by transverse ion heating. The energized ions can then move up to the magnetic field lines and form conics in velocity space. Statistical studies on dayside ion conics pointed out that their temperature increases versus altitude, while their angle with respect to the upward direction (apex) decreases more slowly than expected from adiabatic folding (Peterson et al., 1992; Miyake at al., 1993). Such results are consistent with a gradual heating of ions along the geomagnetic field lines. In some cases, transverse ion heating may be accompanied by a stage of parallel acceleration (Klumpar et al., 1984). In that case, electron data may be used as a probe of field-aligned potential drops, as we will see in this paper.

Because all ionospheric species achieved non-thermal energies when observed in the cusp/cleft, transverse heating is caused by the perpendicular component of the electric field oscillating within some frequency range (André and Yau, 1997). Recent statistical observations from the Freja (Norqvist et al., 1998) and FAST (Lund et al., 2000) satellites pointed out that a major part of ion transverse heat- 
ing events are associated with an enhancement of the broadband, extremely low frequency (BBELF) wave turbulence. The BBELF turbulence covers frequencies from less than $1 \mathrm{~Hz}$ up to several hundred $\mathrm{Hz}$, thus including the $\mathrm{H}^{+}$and $\mathrm{O}^{+} \mathrm{O}^{+}$gyrofrequencies at altitudes from about $1000 \mathrm{~km}$ up to a few $R_{E}$. Its profile versus frequency generally exhibits a power law spectrum, which may be modelled by an index $\alpha$. Many wave modes may be contained in the BBELF turbulence, such as narrow-band electromagnetic ion cyclotron waves (Erlandson et al., 1994), electrostatic ion cyclotron waves (Bonnell et al., 1996), slow ion acoustic waves (Wahlund et al., 1998), and inertial Alfvén waves Dopplershifted by the satellite motion (Stasiewicz et al., 2000). Recently, Angelopoulos et al. (2001) used three-dimensional electric field measurements to find the main component in the BBELF turbulence from cusp crossings by the Polar satellite at an altitude of $6000 \mathrm{~km}$. After separating spatial and temporal variations, the authors pointed out that the main component is consistent with a two-dimensional turbulence, possibly generated by drift or shear instabilities, with phase velocities lower than the satellite velocity, wavelengths shorter than the ion gyroradii, and frequencies lower than ion gyrofrequencies. Therefore, this turbulence cannot heat the ions efficiently. Such a result implies that ion heating is probably induced by a minor component in the BBELF domain.

In terms of ion energization, the theory of ion cyclotron resonance (ICR) heating by the electromagnetic left-hand circular polarized (LHCP) component around the ion gyrofrequencies (Chang et al., 1986) seems the most plausible mechanism. Adopting a power law, altitude-dependent ion heating profile and computing Monte-Carlo simulations, many authors confirmed that only a small fraction of the wave intensity in the BBELF spectrum is needed to cause the observed ion energies through ICR heating (Retterer et al., 1987; Crew et al., 1990; André et al., 1990; Norqvist et al., 1996).

This paper reports on a statistical study of energization mechanisms in the dayside cusp/cleft using particle instruments aboard the Interball-2 satellite. The focus here is on seeking the altitude dependence of ion transverse heating for a large number of cusp/cleft crossings. Because wave measurements were unavailable during the exploration of Interball-2, we needed to develop a procedure describing how particle measurements may be used as constraints in determining the altitude dependence of the heating. The results of this method, independent from wave observations, may be then compared with those from the previous studies. The work has been accomplished on the basis of a large set of numerical simulations from a two-dimensional, trajectorybased code, as studied in detail in the first companion paper (Bouhram et al., 2003).

The outline of the paper is as follows. In Sect. 2, we show two examples of data from Interball-2 associated with transverse ion heating, and where the presence of other acceleration mechanisms, such as field-aligned potential drops, may be ruled out. In contrast, we also present a case associated with field-aligned potential drops. The procedure of deter- mining the altitude dependence of ICR heating is described in Sect. 3, and tested from the events shown in Sect. 2. Then, we apply the procedure to a large number of transverse ion heating events in the dayside cusp/cleft and present a statistical survey of the results. In Sect. 4, other mechanisms, such as field-aligned potential drops, or transverse heating by lower-hybrid waves, are studied qualitatively and their occurrence versus magnetic local time (MLT) is also discussed. A summary of our conclusions is given in Sect. 5 .

\section{Examples of transverse ion heating events}

The Interball-2 satellite was launched on August 1996, into a $19200 \times 750 \mathrm{~km}$ orbit with $62.5^{\circ}$ inclination. During most of the activity period of Interball-2, the wave experiments were unavailable in the dayside cusp/cleft. Therefore, only particle experiments may be used to identify ion energization mechanisms. The Interball-2 satellite carries two particle instruments. The Hyperboloid ion mass spectrometer measures 3-D distributions of $\mathrm{H}^{+}, \mathrm{He}^{+}, \mathrm{O}^{+}$and $\mathrm{O}^{++}$ions at $1-80 \mathrm{eV}$ (Dubouloz et al., 1998). At thermal energies $(<10 \mathrm{eV})$, ion measurements are often shielded because of the positive value of the satellite electric potential with respect to the plasma. Therefore, a filling-in procedure, similar to that used by Su et al. (1998) to correct polar wind measurements, has been developed in order to extend the measured distribution to low energy (Bouhram, 2002a). The ION experiment provides energy spectra of $\mathrm{H}^{+}, \mathrm{O}^{+}$ions and electrons at higher energies $(30 \mathrm{eV}-15 \mathrm{keV})$ over two view directions, which rotate in the spin plane along with the satellite (Sauvaud et al., 1998). Note when the satellite is in the auroral and polar regions, an angle appears between the geomagnetic field and the detectors spin plane. Therefore, the parallel and anti-parallel directions are not scanned. Usually, only pitch angles between $30^{\circ}$ and $150^{\circ}$ are scanned by the detectors. For these reasons, it is difficult to study ion beams at high energy $(>100 \mathrm{eV})$. When studying ion conics, the same filling-in procedure as mentioned above has been applied to fit the missing portion in angle. From both experiments, ion distribution functions and moments of major species are recorded every spin period (120 s), by covering a continuous and wide energy range $(1 \mathrm{eV}-15 \mathrm{keV})$.

\subsection{Transverse heating event 1}

Figure 1 shows $40 \mathrm{~min}$ of data from a pass through the cusp around noon at about $2.5 R_{E}$ altitude, during a period of moderate geomagnetic activity $\left(K_{p}=2\right)$. At the beginning of the time interval, Interball-2 was on closed field lines, as evidenced by substantial $\mathrm{H}^{+}$flux with high energies (up to $10 \mathrm{keV}$ ) in Fig. 1b, accompanied by a denser, low-energy $(<10 \mathrm{eV})$ component (Fig. 1c). From about 21:26 UT, a sudden onset of transverse ion heating is detected from $\mathrm{O}^{+}$ measurements. Right after the onset, the $\mathrm{H}^{+}$high-energy panel (Fig. 1b) shows a background population with a timeenergy dispersion, characteristic of magnetosheath injections 
(a)

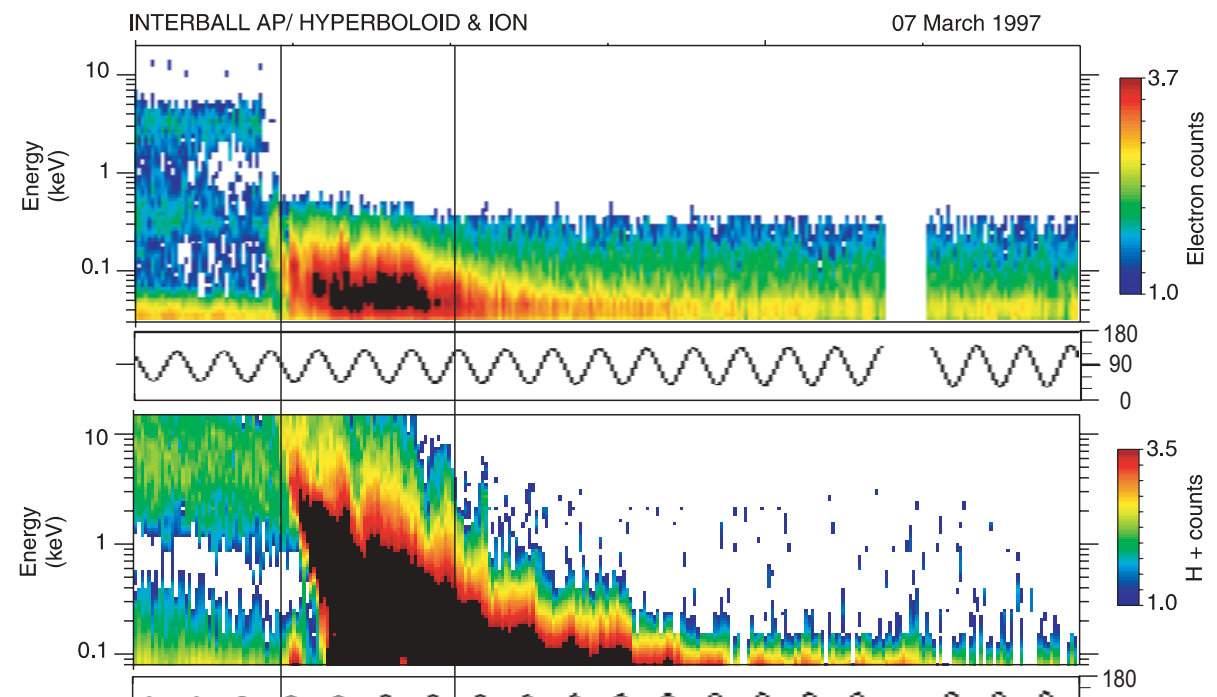

(c)

(b)

(d)

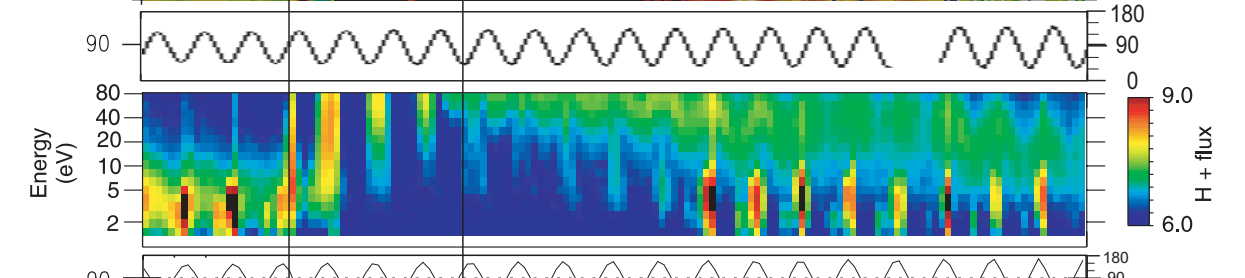

(e)

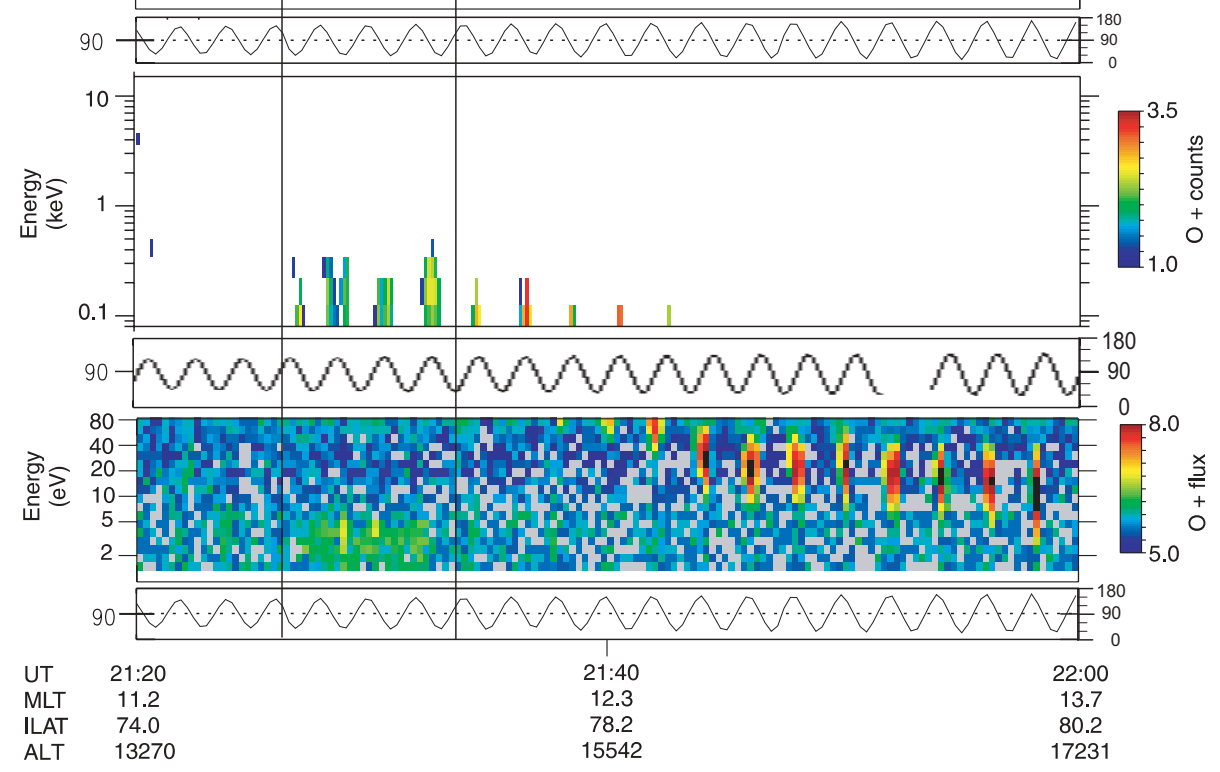

Fig. 1. Overview of a transverse ion heating event on 7 March 1997, between 21:20 and 22:00 UT. From top to bottom: energy-time spectrograms of (a) $30 \mathrm{eV}$ to $15 \mathrm{keV}$ electrons, (b) $30 \mathrm{eV}$ to $15 \mathrm{keV} \mathrm{H}^{+}$ions, (c) $1 \mathrm{eV}$ to $80 \mathrm{eV} \mathrm{H}^{+}$ions, (d) $30 \mathrm{eV}$ to $15 \mathrm{keV} \mathrm{O} \mathrm{O}^{+}$ions, and (e) $1 \mathrm{eV}$ to $80 \mathrm{eV} \mathrm{O}^{+}$ions. High-energy measurements in counts are from the ION experiment, while low-energy measurements in $\log \left[\left(\mathrm{m}^{2} \mathrm{~s} \mathrm{sreV}\right)^{-1}\right]$ are measured by the central detector of the Hyperboloid experiment. The vertical black lines indicate the boundaries of the heating region.

(Burch et al., 1982). This observation, along with stronger, low-energy $(<200 \mathrm{eV})$ electron fluxes (Fig. 1a), indicate that the observed heating region is associated with the polar cusp (Newell and Meng, 1988). As Interball-2 travels poleward from the cusp, the observed conical distributions fold up, i.e. become more anti-field-aligned, while their mean energy decreases. This signature may be explained by a transverse ion heating occurring in a region of finite latitudinal extent, in combination with a poleward drift due to the magnetospheric convection (Horwitz, 1986, Knudsen et al., 1994). During this event, the orientation of the interplanetary magnetic field (IMF) is steady and southward ( $B_{x} \sim-2 \mathrm{nT}, B_{y} \sim 0$, and $\left.B_{z} \sim-4 \mathrm{nT}\right)$, which is consistent with convection patterns that are antisunward directed in the polar cap. The outflowing ionospheric $\mathrm{H}^{+}$component is accompanied by a background population that represents the low-energy tail of the magnetosheath component. Depending on the flux intensities and the energy resolution, it is not always possible to 
(a)

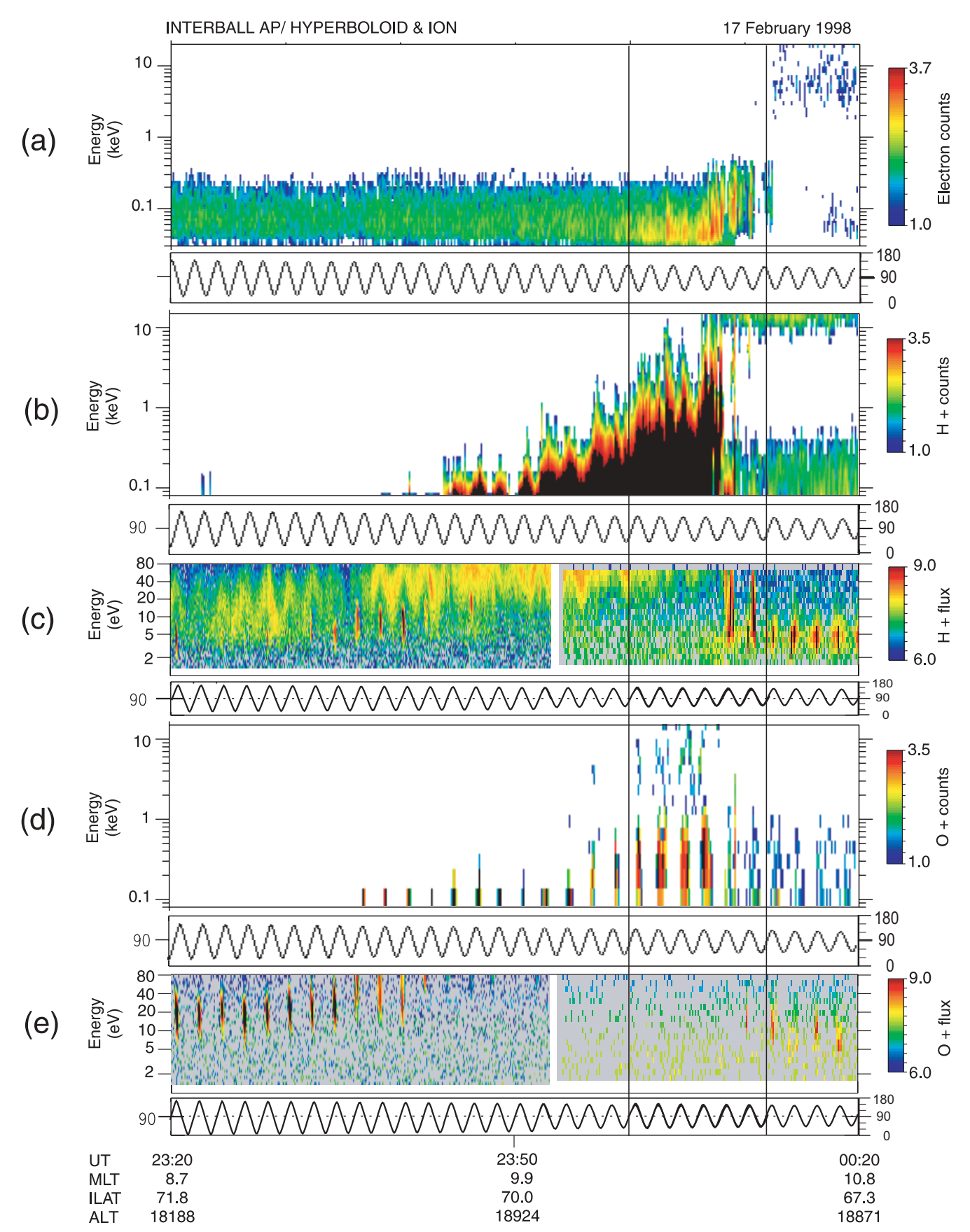

Fig. 2. Overview of a transverse ion heating event on 17 February 1998, between 23:20 and 00:20 UT. The format is the same as for Fig. 1.

separate the ionospheric component from the magnetosheath component.

\subsection{Transverse heating event 2}

Figure 2 shows $1 \mathrm{~h}$ of data from a pass through the dawn polar cap and cusp at about $3 R_{E}$ altitude, during a period of high geomagnetic activity $\left(K_{p}=6\right)$. At the beginning of the time interval, Interball-2 was in the polar cap and low energy outflowing ions are detected. During this event, the orientation of the IMF is steady and strongly southward
$\left(B_{x} \sim B_{y} \sim 2 \mathrm{nT}\right.$, and $\left.B_{z} \sim-14 \mathrm{nT}\right)$, which is consistent with convection patterns that are antisunward directed in the polar cap. This suggests that the ion heating, responsible for the observed outflow, occurs at a lower latitude in the dawn side (8.5-10.5 MLT) of the cusp/cleft region, with ions drifting into the dawn polar cap. As a result of the velocity filtering effect due to the convection drift, the mean energy of upflowing ion species increases as the satellite enters the poleward boundary of the cusp near 00:00 (UT). Once again, the cusp region may be detected from high-energy proton injections and intense, low-energy isotropic electron fluxes. 
(a)

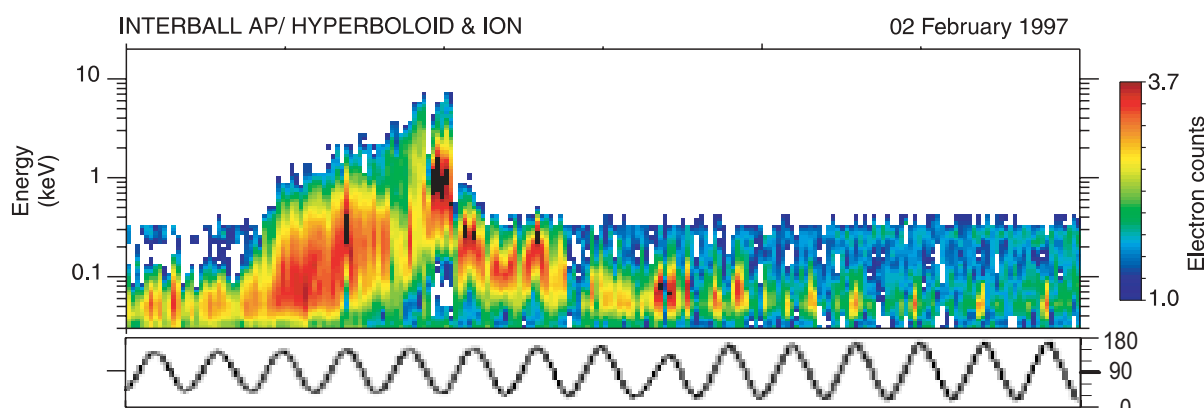

(b)

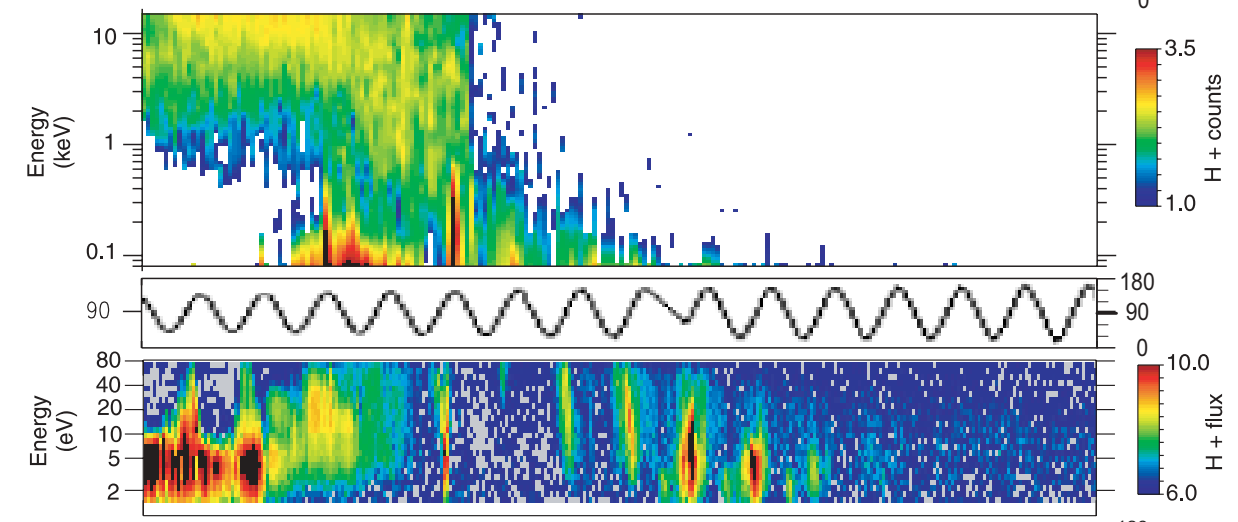

(c)

(d)

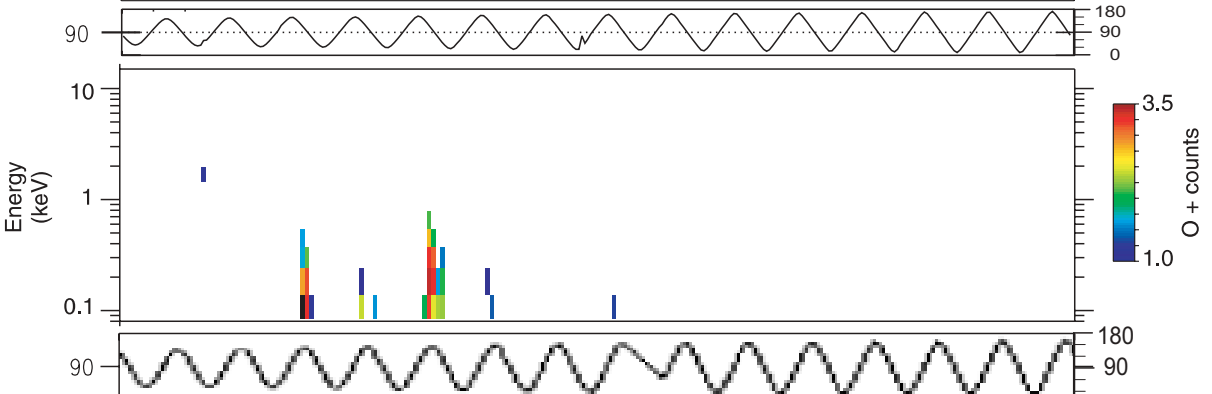

(e)

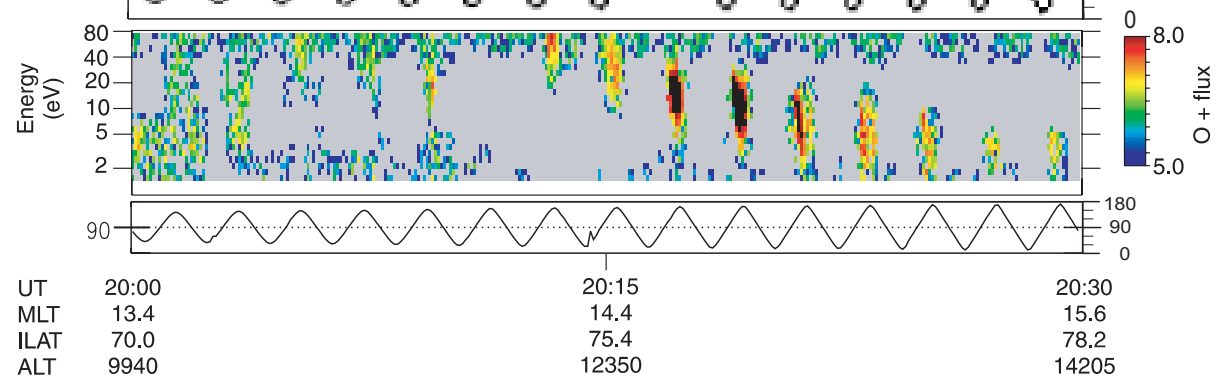

Fig. 3. Overview of a crossing of field-aligned potential drops on 9 February 1997, between 20:00 and 20:30 UT. The format is the same as for Fig. 1.

The region is also correlated with elevated $\mathrm{O}^{+}$conics, with energies extending up to a few $\mathrm{keV}$.

\subsection{Event associated with field-aligned potential drops}

Figure 3 shows 30 min of particle data from a path through the dusk cleft and polar cap. The electron distributions (Fig. 3a) have characteristic energies that contrast with those observed during events 1 and 2 . The signature in the electron spectrogram is typical of regions of field-aligned potential drops. An empirical model of such regions consists of assuming that the satellite crosses a zone of U-shape equipo- tential surfaces (Marklund et al., 1997; Carlson et al., 1998). Due to a lack of temporal resolution, a detailed analysis of such structures is not possible using Interball-2 data. However, on the basis of particle spectrograms, we are able to identify two different regions. Around 20:10 UT, there is a large inverted- $\mathrm{V}$ structure marked by downgoing electrons carrying an upward current, and upgoing $\mathrm{H}^{+}$and $\mathrm{O}^{+}$ions. According to the presence of a field-aligned potential drop (upward electric field) below the satellite, the observed ion distributions have a similar mean parallel energy of about $160 \mathrm{eV}$. However, the presence of non-negligible perpendic- 
ular ion temperatures of about $100 \mathrm{eV}$ indicates that parallel acceleration is accompanied by transverse ion heating along the field line. Just poleward of the inverted- $\mathrm{V}$, after 20:15 UT, there is a downward return current region associated with downward DC electric fields. This region is indicated by upgoing electrons with a mean parallel energy of a few tens of eV. Inside the same time interval, between 21:15 and 21:21 UT, Fig. $3 \mathrm{c}$ and plots in velocity phase space (not shown) indicated the presence of warm upgoing $\mathrm{H}^{+}$conics with a downgoing component. This is a classical picture of the pressure cooker effect by Gorney et al. (1985); the downward DC electric field holds the ion down in a region of transverse heating until it achieves sufficient parallel energy via the mirror force to overcome the electric potential barrier. For a 1-D theory of the pressure cooker effect that calculates the magnitude of the DC electric field, see Jasperse et al. (1998). Note that no downgoing component is detected in the low-energy $\mathrm{O}^{+}$spectrogram (Fig. 3e), probably due to a lack of instrument sensitivity, with $\mathrm{O}^{+}$fluxes being two orders of magnitude smaller than $\mathrm{H}^{+}$fluxes.

\section{Altitude dependence of ion transverse heating}

\subsection{Procedure}

In a first paper (Bouhram et al., 2003), we developed a twodimensional, Monte Carlo, trajectory-based code for ion outflow from the dayside cusp/cleft, which is associated with transverse ion heating. A scheme of the simulation model is available in Fig. 1 of Bouhram et al. (2003). In the model, the coordinate system in space is described by the geocentric distance $s$ and an abscissa $X$, that represents the horizontal distance from the equatorward boundary of the heating region and is normalized with respect to its horizontal width $\Delta$. Because of the finite extent of the heating region, the effect of poleward convection drift $v_{p}$ leads to a limited residence time $t_{D}=\Delta / v_{p}$ of ions when being energized. In the heating region, we modelled the effect of wave-particle interactions by a transverse heating through ion cyclotron resonance (ICR) from a BBELF power law spectrum assumed to be uniform versus altitude. Then, the altitude dependence of the ICR heating rate might be modeled as follows:

$$
\dot{W}_{i \perp}(s)=\dot{W}_{i \perp}\left(s_{0}\right) \times\left(s / s_{0}\right)^{3 \alpha},
$$

where $\dot{W}_{i \perp}\left(s_{O}\right)=\left(q_{i}^{2} / 2 m_{i}\right) S_{L}\left[\left(f_{c i}\left(s_{o}\right)\right)\right]$ denotes the heating rate for a type of ion $i$ at the lower boundary distance $s_{0}$, and $\alpha$ is the spectral index. We also defined a parameter $w_{0}$ proportional to ion heating rates at a reference $s_{0}$. This additional parameter does not depend on the type of ion and is given by:

$$
\begin{gathered}
w_{0}=\left(\frac{m_{H}}{2}\right)^{1 / 3}\left[s_{0} \dot{W}_{i \perp}\left(s_{0}\right) M_{i}^{1-\alpha}\right]^{2 / 3}= \\
\left(\frac{m_{H}}{2}\right)^{1 / 3}\left[s_{0} \dot{W}_{H \perp}\left(s_{0}\right)\right]^{2 / 3} .
\end{gathered}
$$

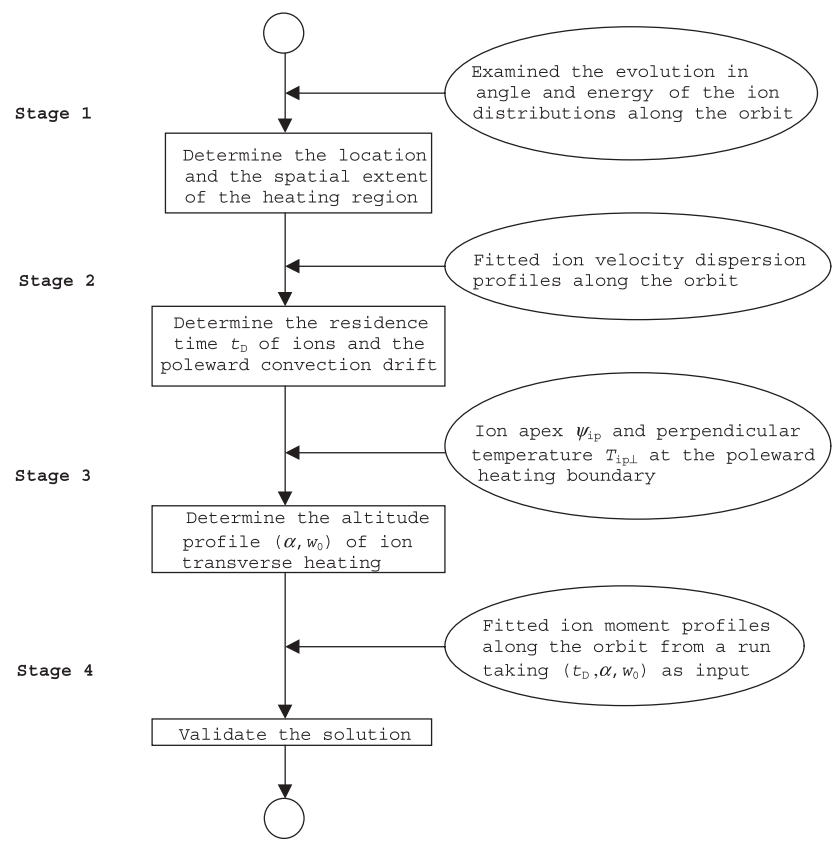

Fig. 4. Flow chart of the procedure applied to determine the parameters associated with transverse heating and the horizontal transport.

The model allowed us to study the characteristics of ion conics at the poleward boundary of the heating region, along with the transport patterns of ion field-aligned flows in the polar cap, as functions of a reasonable number of simulation parameters $\left(t_{D}, w_{0}, \alpha\right)$.

Here, we developed a procedure in order to reverse the process, i.e. to find the altitude dependence of ion transverse heating from ion measurements at high altitudes $\left(1.5-3 R_{E}\right)$ by the Interball-2 satellite during a large number of events. The procedure results in four stages that are summarized in the flow chart of Fig. 4 and are discussed in the following sections.

\subsubsection{Stage 1}

Because simulations have been computed in a coordinate system where horizontal scaling has a normalized unit, we need to determine as a first stage the location of the heating region along with its latitudinal extent. In Sect. 2, it has been shown that the location of the equatorward border of the heating region is obvious from the sudden onset of ion energization in spectrograms. On the other hand, the determination of the poleward heating boundary (PHB) requires a further analysis of energy and pitch-angle characteristics of ion distributions along the satellite track, as discussed in Sect. 3.2.1.

\subsubsection{Stage 2}

Next, before determining the parameters $\left(w_{0}, \alpha\right)$ associated with the heating profile versus altitude, we need to estimate the residence time of ions $t_{D}$ inside the heating region, or 
the magnitude of the poleward convection drift $u_{p}$. At the Interball-2 altitude, the convection drift (a few $\mathrm{km} / \mathrm{s}$ ) is much smaller than the typical ion upward velocities, and also much smaller than the change in velocity between two energy channels of the Hyperboloid instrument. Therefore, ion distributions cannot be used reliably for calculating $u_{p}$. However, using simulation results, the estimation of $t_{D}$ is possible by investigating the dispersive patterns of ion upward velocities along the satellite track, as illustrated in Sect. 3.2.2.

\subsubsection{Stage 3}

Providing $t_{D}$ is known, the parameters $\left(w_{0}, \alpha\right)$ may be determined from the perpendicular mean energy $w_{\perp i p}$ and the $\operatorname{apex} \Psi_{i p}=\arctan \left[\left(w_{\perp i p} / w_{\| i p}\right)^{1 / 2}\right]$ of the observed ion conics at the poleward border of the heating region. In doing so, we have utilized a graphical method based on the results of a parametric study which established distribution patterns of $w_{\perp i}$ and $\Psi_{i}$ in a $w_{0}-\alpha$ diagram (Bouhram et al., 2003).

\subsubsection{Stage 4}

Applying all the previous stages leads to an average solution $\left(t_{D}, w_{0}, \alpha\right)$ of the problem. Furthermore, the consistency of this solution may be tested by taking the parameters $\left(t_{D}, w_{0}, \alpha\right)$ as input to a simulation. Then, we can compare ion moment profiles from the simulation with those measured along the satellite track.

\subsection{Results}

In the following (Sect. 3.2), the four stages are worked out in detail, by being applied to the first two events described in Sect. 2.

\subsubsection{Location of the poleward heating boundary}

Figure 5 shows three $\mathrm{O}^{+}, \mathrm{H}^{+}$velocity distributions recorded by the ION experiment near the poleward edge of the heating region for the two previous data sets. In these plots, ion distributions are displayed versus increasing latitudes. In the first left-hand side two panels for both events, we observe ion conics with a net upward velocity component. This shape is consistent with transverse ion energization occurring over a wide altitude range up to the satellite orbit, with weakly heated ions (i.e. of lower energies) being spread out poleward from the heating region by the convection drift. In the middle plot for both cases, the observed ion conics are more extended at high energies in an oblique direction corresponding to an apex angle of $40-50^{\circ}$. This is unlikely to support the scenario of a parallel acceleration by an upward DC electric field. Conversely, because intense electron fluxes are detected at moderate energies $(<200 \mathrm{eV})$ during both events (see Fig. 1 and Fig. 2), the presence of a significant downward DC electric field may be ruled out.

The survey versus latitude of the recorded ion distributions allows us to locate the PHB accurately. For both cases, between the middle and the right-hand side plots, $\mathrm{O}^{+}$conics fold up, i.e. become more upward shifted by an amount in pitch angle of about $20-30^{\circ}$. So far in the first companion paper, it has been pointed out that, because the particle's motion is adiabatic poleward to the heating region, the conical shape of ion distributions turns rapidly upward while the ion mean energy and temperatures fall down. Indeed, the satellite crossed the PHB between 21:32:45 and 21:33:45 UT at $\Lambda_{p} \sim 77.0^{\circ}$, and between 23:58:55 and 23:59:55 UT at $\Lambda_{p} \sim 69.2^{\circ}$ for events 1 and 2, respectively. For both cases, this location also coincides with the poleward cusp boundary, as inferred from electron spectrograms with flux intensities (see Fig. 1 and Fig. 2).

Providing the PHB is determined, the ion conic parameters at this location may be used as constraints to find out the altitude dependence of ion heating. Table 1 summarizes the ion moments at the PHB for events 1 and 2. When calculating the densities associated with those conics, it is necessary to include the missing portion at pitch angles close to the upward direction. In doing so, we developed an iterative filling-in procedure, assuming a bi-maxwellian distribution in the missing domain (Bouhram, 2002a). It is obvious that a distribution having a conical shape cannot be entirely fitted by a bi-maxellian. However, this assumption is used only in order to correct the ion densities. Indeed, when the peak flux of the observed conics is at pitch angles lower than the upper limit scanned by ION, moments of first and second order (mean velocity, temperatures) are weakly modified. Usually, when adding the missing portion, the density increases from $\sim 10 \%$ up to $\sim 50 \%$. In Fig. 4, we have plotted the distributions after completing the filling-in process that extends phase-space density patterns in the domain not scanned.

For both ION and Hyperboloid experiments, there are other origins of uncertainties that may be estimated when calculating ion moments: the Poisson statistics error estimation $\varepsilon_{1}$ associated with the individual measurements (ion counts), the uncertainty $\varepsilon_{2}$ due to applying the filling-in procedure, the errors $\varepsilon_{3}$ and $\varepsilon_{4}$ associated with the limited resolution of the instruments in angle and energy, respectively. The fractional error due to counting statistics is approximately equal to the fractional error associated with the peak of the distribution, i.e. $\varepsilon_{1} \sim 1 / C_{i}{ }^{1 / 2}$ where $C_{i}$ is number of counts. The error $\varepsilon_{2}$ corresponds to the difference between the measured and the corrected density. Hence, since the errors $\varepsilon_{1}$ and $\varepsilon_{2}$ are uncorrelated, the uncertainty in the density is equal to $\left(\varepsilon_{1}^{2}+\varepsilon_{2}^{2}\right)^{1 / 2}$. The errors associated with the apex angle and the mean energy are roughly equal to the instrument pitch angle and energy resolution $(\Delta \theta, \Delta E)$, where the peak is detected (see Fig. 5), i.e. $\varepsilon_{3} \sim \Delta \theta$ and $\varepsilon_{4} \sim \Delta E$. Usually, the major uncertainty lies in those associated with the ion densities. But there still is a considerable uncertainty in the mean energy when the peak of the conic is located in the first energy channel, as it is often the case for $\mathrm{H}^{+}$ions.

\subsubsection{Determination of the residence time}

In the companion paper (Bouhram et al., 2003), it has been pointed out that the dispersive patterns of ion upward veloci- 

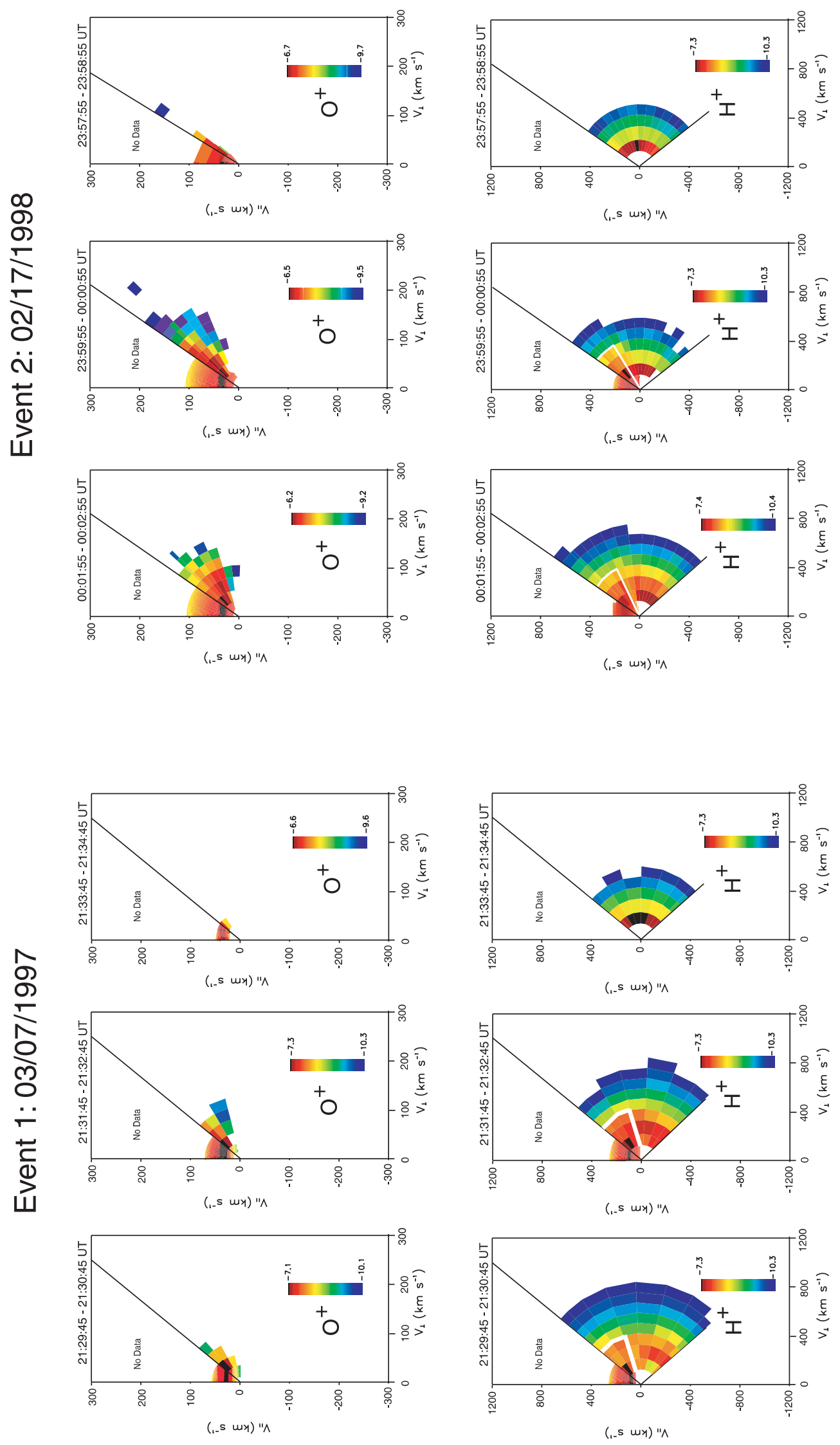

Fig. 5. Ion distribution functions in $\mathrm{cm}^{-3} \mathrm{~km}^{-3} \mathrm{~s}^{3}$ recorded near the poleward heating boundary during event 1 (left-hand side) and event 2 (right-hand side). 
Table 1. List and values of $\mathrm{H}^{+}$and $\mathrm{O}^{+}$moments associated with the observed conics at the poleward heating boundary during events 1 and 2

\begin{tabular}{lccc}
\hline \multicolumn{1}{c}{ Definition } & Notation & Value (event 1) & Value (event 2) \\
\hline $\mathrm{H}^{+}$density & $n_{H p}$ & $1.03 \pm 0.31 \mathrm{~cm}^{-3}$ & $0.91 \pm 0.20 \mathrm{~cm}^{-3}$ \\
$\mathrm{H}^{+}$upward mean velocity & $u_{H p}$ & $102 \pm 27 \mathrm{~km} \mathrm{~s}^{-1}$ & $145 \pm 27 \mathrm{~km} \mathrm{~s}^{-1}$ \\
$\mathrm{H}^{+}$mean energy & $w_{H p}$ & $170 \pm 90 \mathrm{eV}$ & $410 \pm 85 \mathrm{eV}$ \\
$\mathrm{H}^{+}$perpendicular mean energy & $w_{H \perp p}$ & $90 \pm 30 \mathrm{eV}$ & $215 \pm 80 \mathrm{eV}$ \\
$\mathrm{H}^{+}$parallel mean energy & $w_{H \| p}$ & $80 \pm 40 \mathrm{eV}$ & $195 \pm 80 \mathrm{eV}$ \\
$\mathrm{H}^{+}$apex & $\Psi_{H p}$ & $48.2 \pm 3.9^{\circ}$ & $44.3 \pm 2.5^{\circ}$ \\
$\mathrm{O}^{+}$density & $n_{O p}$ & $0.02 \pm 0.01 \mathrm{~cm}^{-3}$ & $0.30 \pm 0.10 \mathrm{~cm}^{-3}$ \\
$\mathrm{O}^{+}$upward mean velocity & $u_{O p}$ & $41.6 \pm 4.0 \mathrm{~km} \mathrm{~s}^{-1}$ & $71.5 \pm 3.5 \mathrm{~km} \mathrm{~s}^{-1}$ \\
$\mathrm{O}^{+}$mean energy & $w_{O p}$ & $570 \pm 110 \mathrm{eV}$ & $960 \pm 90 \mathrm{eV}$ \\
$\mathrm{O}^{+}$perpendicular mean energy & $w_{O p}$ & $300 \pm 100 \mathrm{eV}$ & $440 \pm 80 \mathrm{eV}$ \\
$\mathrm{O}^{+}$parallel mean energy & $w_{O \| p}$ & $270 \pm 100 \mathrm{eV}$ & $520 \pm 85 \mathrm{eV}$ \\
$\mathrm{O}^{+}$apex & $\Psi_{O p}$ & $45.8 \pm 3.9^{\circ}$ & $40.2 \pm 2.5^{\circ}$ \\
\hline
\end{tabular}
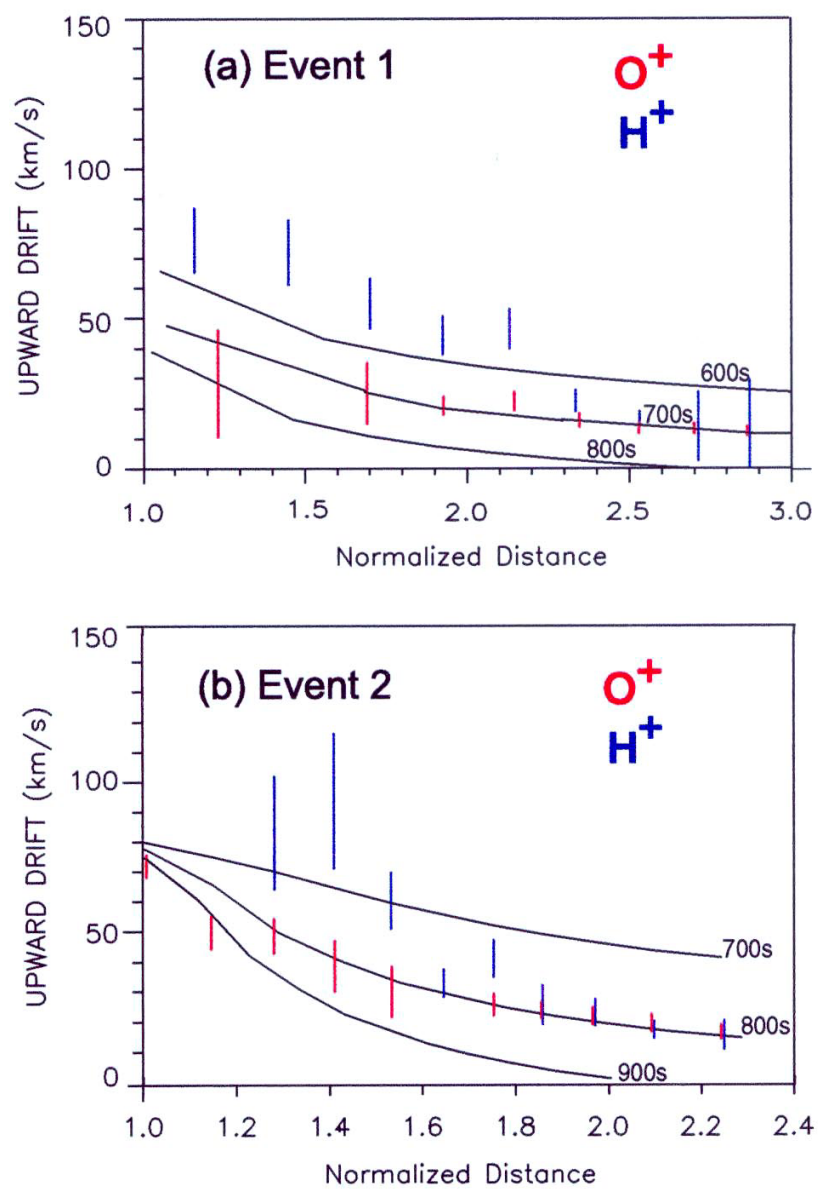

Fig. 6. Comparisons of dispersive patterns of ion upward velocities observed along the satellite track with those from numerical simulations using different values of $t_{D}$.

ties, usually observed poleward to the heating region at high altitude, are entirely controlled by the parameter $t_{D}$ at horizontal distances higher than $X \sim 1.5$. Figure 6 shows the upward mean velocities of ionospheric $\mathrm{H}^{+}$and $\mathrm{O}^{+}$ions as functions of $X$ along the satellite track. The solid curves show the dispersive profiles $u_{i}[X(s)]$ for different values of $t_{D}$ as obtained from numerical simulations (Bouhram et al., 2003). From Fig. 6, it is clear that residence times of roughly 700 and $800 \mathrm{~s}$ are consistent with the data associated with events 1 and 2, respectively. For both events, the latitudinal width of the heating region is about $1.3^{\circ}$ that corresponds to a ground distance of $145 \mathrm{~km}$. This implies a poleward ionospheric convection drift of about 210 and $180 \mathrm{~m} \mathrm{~s}^{-1}$ for events 1 and 2, respectively. Unfortunately, convection measurements from another source of data are unavailable during these periods to see whether our estimates are correct or not. One alternative possibility is to make comparisons with statistical convection maps inferred from many sources of ground and satellite measurements (Weimer, 1995; Ruohoniemi and Greenwald, 1996; Papitaschvili and Rich, 2002; to name just a few). However, let us note that such models based on the IMF are only statistically correct and cannot be used for a case study without risk of significant errors if modeling the horizontal transport of ionospheric ions. One critical aspect is that all available models depend heavily on many assumptions about the ionospheric conductivities when inferring convection maps (Papitaschvili and Rich, 2002). Therefore, as also concluded by Papitaschvili and Rich (2002), the development of a unified approach for the modeling of high-latitude convection from various sources of data is definitely needed. Regardless of this problem, we made graphical estimations of the poleward convection drift from the model of Ruohoniemi and Greenwald (1996) for a southward IMF orientation. We estimated a poleward drift of $200-300 \mathrm{~m} \mathrm{~s}^{-1}$ which is at least of the same order as those inferred from the velocity dispersion method.

\subsubsection{Transverse heating profile versus altitude}

Figure 7 shows the patterns of $w_{\perp i p}$ and $\Psi_{i p}$ at the PHB in a $w_{0}-\alpha$ plane for the values of $t_{D}$ determined in Sect. 3.2.2 and the altitude of Interball-2. From the measurements of $w_{\perp i p}$ and $\Psi_{i p}$, as listed in Table 1, we can determine graph- 
Table 2. List and values of parameters used as input to numerical simulations that have been applied to events 1 and 2

\begin{tabular}{lccc}
\hline \multicolumn{1}{c}{ Definition } & Notation & Value (Event 1) & Value (Event 2) \\
\hline Residence time & $t_{D}$ & $700 \mathrm{~s}$ & $800 \mathrm{~s}$ \\
Energization parameter & $w_{0}$ & $5 \mathrm{eV}$ & $20 \mathrm{eV}$ \\
Spectral index & $\alpha$ & 1.3 & 0.8 \\
$\mathrm{O}^{+}$density at $z=1000 \mathrm{~km}$ & $n_{O 0}$ & $800 \mathrm{~cm}^{-3}$ & $2500 \mathrm{~cm}^{-3}$ \\
$\mathrm{O}^{+}$velocity at $z=1000 \mathrm{~km}$ & $u_{O 0}$ & $0.5 \mathrm{~km} \mathrm{~s}^{-1}$ & $0.5 \mathrm{~km} \mathrm{~s}^{-1}$ \\
$\mathrm{O}^{+}$density at $X=0$ and $z=z_{\text {sat }}$ & $n_{O e}$ & $0.05 \mathrm{~cm}^{-3}$ & $0.3 \mathrm{~cm}^{-3}$ \\
$\mathrm{O}^{+}$flux at $z=1000 \mathrm{~km}$ & $J_{O 0}$ & $4.0 \times 10^{7} \mathrm{~cm}^{-2} \mathrm{~s}^{1}$ & $2.5 \times 10^{8} \mathrm{~cm}^{-2} \mathrm{~s}^{1}$ \\
$\mathrm{H}^{+}$density at $z=1000 \mathrm{~km}$ & $n_{H 0}$ & $500 \mathrm{~cm}^{-3}$ & $600 \mathrm{~cm}^{-3}$ \\
$\mathrm{H}^{+}$velocity at $z=1000 \mathrm{~km}$ & $u_{H 0}$ & $2.0 \mathrm{~km} \mathrm{~s}^{-1}$ & $2.0 \mathrm{~km} \mathrm{~s}^{-1}$ \\
$\mathrm{H}^{+}$density at $X=0$ and $z=z_{\text {sat }}$ & $n_{H e}$ & $0.1 \mathrm{~cm}^{-3}$ & $0.1 \mathrm{~cm}^{-3}$ \\
$\mathrm{H}^{+}$flux at $z=1000 \mathrm{~km}$ & $J_{H 0}$ & $1.0 \times 10^{8} \mathrm{~cm}^{-2} \mathrm{~s}^{-1}$ & $1.2 \times 10^{8} \mathrm{~cm}^{-2} \mathrm{~s}^{-1}$ \\
\hline
\end{tabular}

Event $1: 03 / 07 / 1997$
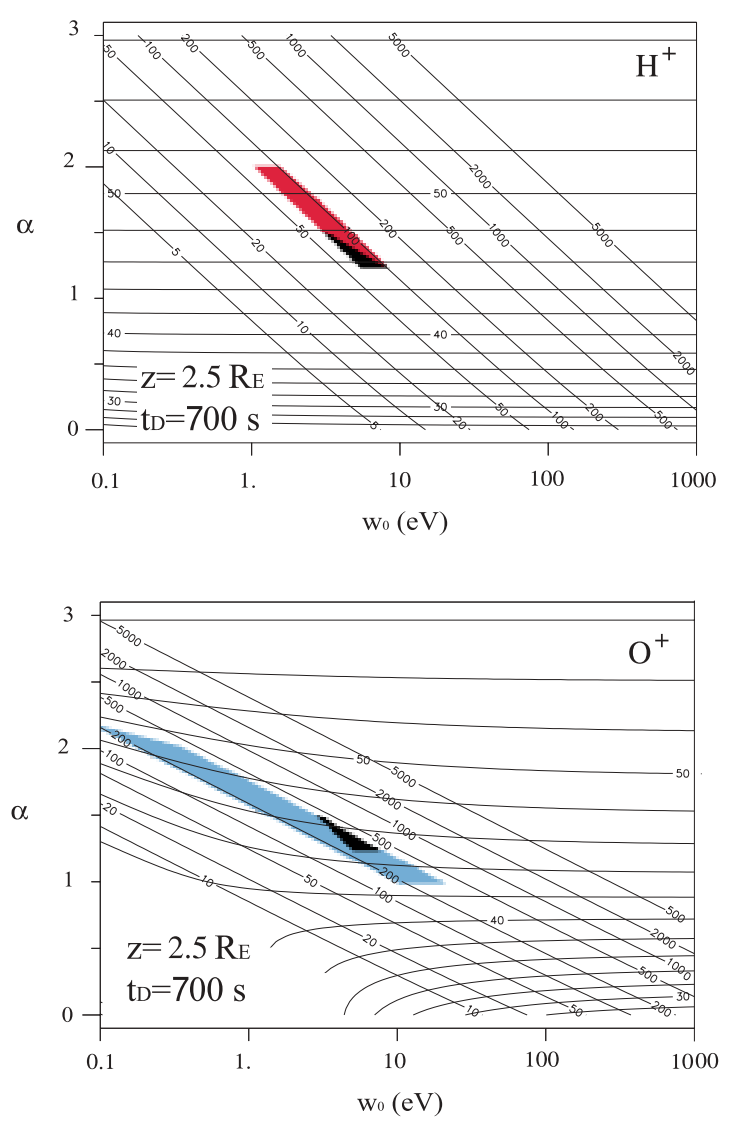

Event $2: 02 / 17 / 1998$
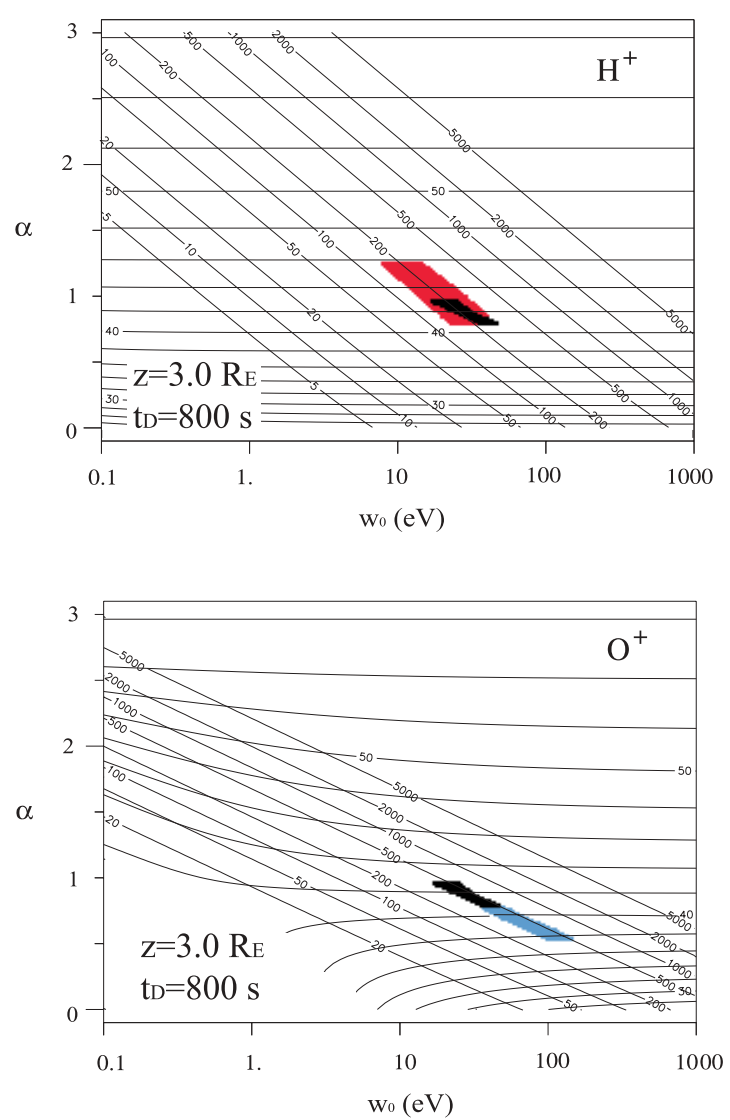

Fig. 7. Graphical method used to determine the parameters associated with the altitude dependence of ion transverse heating.

ically the couple of parameters $\left(w_{0}, \alpha\right)$ associated with the heating profile versus altitude. Because there are uncertainties in the estimation of $w_{\perp i p}$ and $\Psi_{i p}$, we find a domain of solutions centered around a mean solution. In Fig. 7, we have represented by a colour surface the solution associated with the type ion $\left(\mathrm{H}^{+}\right.$or $\left.\mathrm{O}^{+}\right)$, and by a black surface the intersection between the solutions associated with $\mathrm{H}^{+}$and $\mathrm{O}^{+}$. The obtained mean solutions are $\left(w_{0}=5 \mathrm{eV}, \alpha=1.3\right)$ and $\left(w_{0}=20 \mathrm{eV}, \alpha=0.8\right)$ for events 1 and 2, respectively.

\subsubsection{Additional test}

The mean solutions of the heating profile versus altitude obtained for events 1 and 2 may be tested by being introduced as input to numerical simulations. The simulations are computed from the model described in Bouhram 

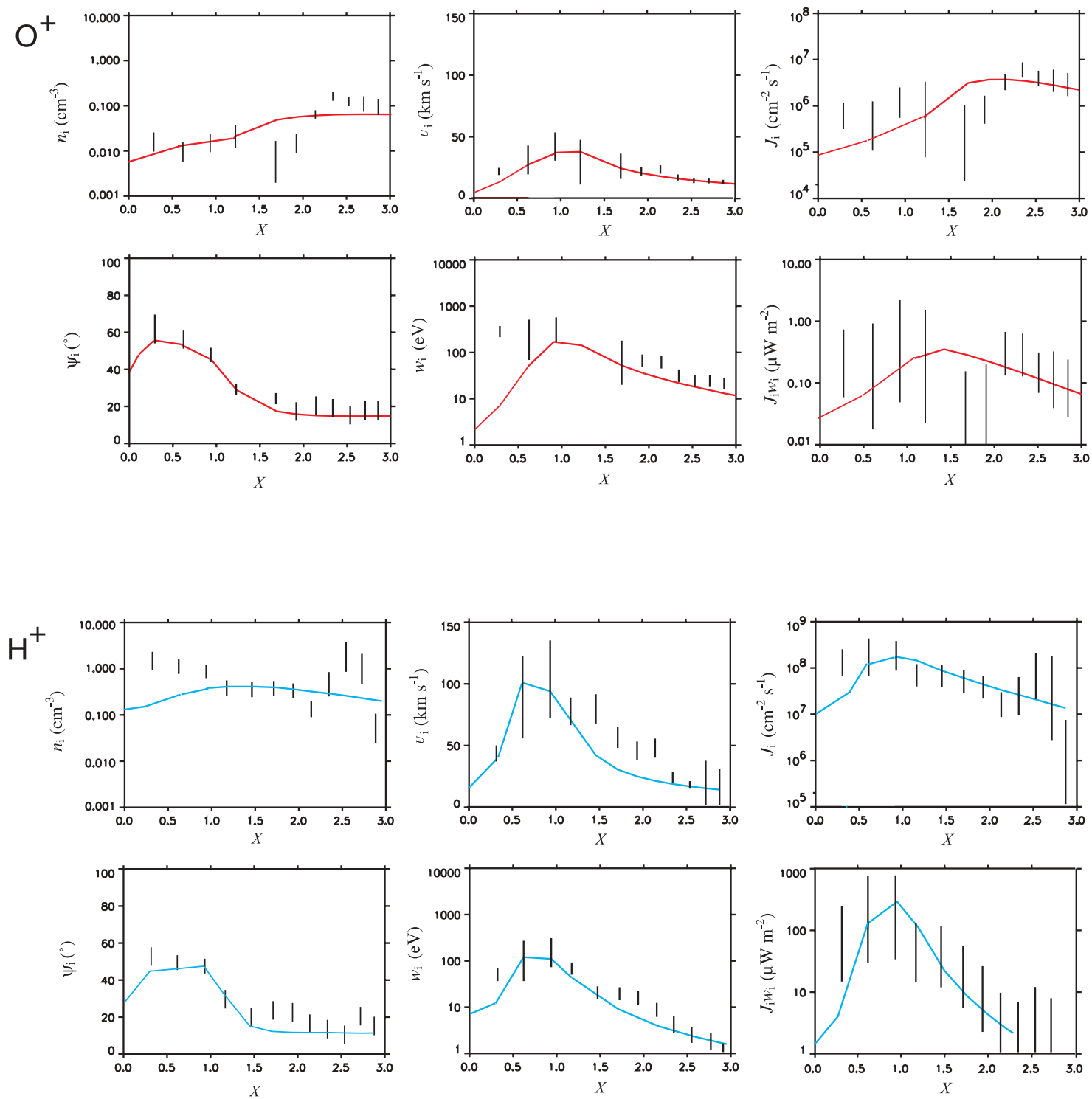

Fig. 8. Comparisons of experimental ion moments along the satellite track for event 1 with those from a numerical simulation (solid curves) for $\mathrm{O}^{+}$(top) and $\mathrm{H}^{+}$(bottom).

et al. (2002a). The names of input parameters are summarized in Table 2, along with their values for both events. As onset to a simulation, we introduce a ionospheric ion source $\mathrm{S}_{\mathrm{i} 0}$ at $z=1000 \mathrm{~km}$, characterized by a density $n_{i 0}$ and a flux $J_{i 0}$, and a component $S_{\text {ie }}$ along the equatorward edge of the heating region with a density $n_{i e}$ at Interball-2 altitude $z_{\text {sat }}$. This latest component allows us to reproduce the patterns of ion moments near the equatorward heating boundary. The value of $n_{i e}$ is inferred from Hyperboloid measurements just equatorward from the heating region, since there energization processes are less important. Therefore it is reasonable to assume that the density is inversely proportional to the cross-section area $A(s)=\left(s / s_{0}\right)^{3}$ of a magnetic flux tube, so as to satisfy the particle conservation law. The values of $n_{i 0}$ and $J_{i 0}$ are adjusted so as to reproduce the densities and fluxes observed at the Interball-2 altitude poleward from the heating region.

Figures 8 and 9 show the moment profiles versus $X$ along the satellite track for events 1 and 2 , respectively. In these plots, for a type of ion i, the fluence $J_{i}$ is defined by the product $A(s) \times n_{i}(s, X) \times u_{i}(s, X)$ and $J_{i} w_{i}$ corresponds to the energy density flux. The uncertainties represented by vertical lines correspond to those discussed in Sect. 3.1.1. The major uncertainty is those associated with the ion densities, with the uncertainty due to the limited angular and energy resolution of instruments being less important. The uncertainties are more important for $J_{i}$ and $J_{i} w_{i}$ because these include all uncertainties mentioned above. For both data sets, the simulated ion moments follow the tendencies of those observed. A few disagreements are observed locally and may be explained by the assumption of a steady-state model associated with a finite number of parameters. In the simulations, the 

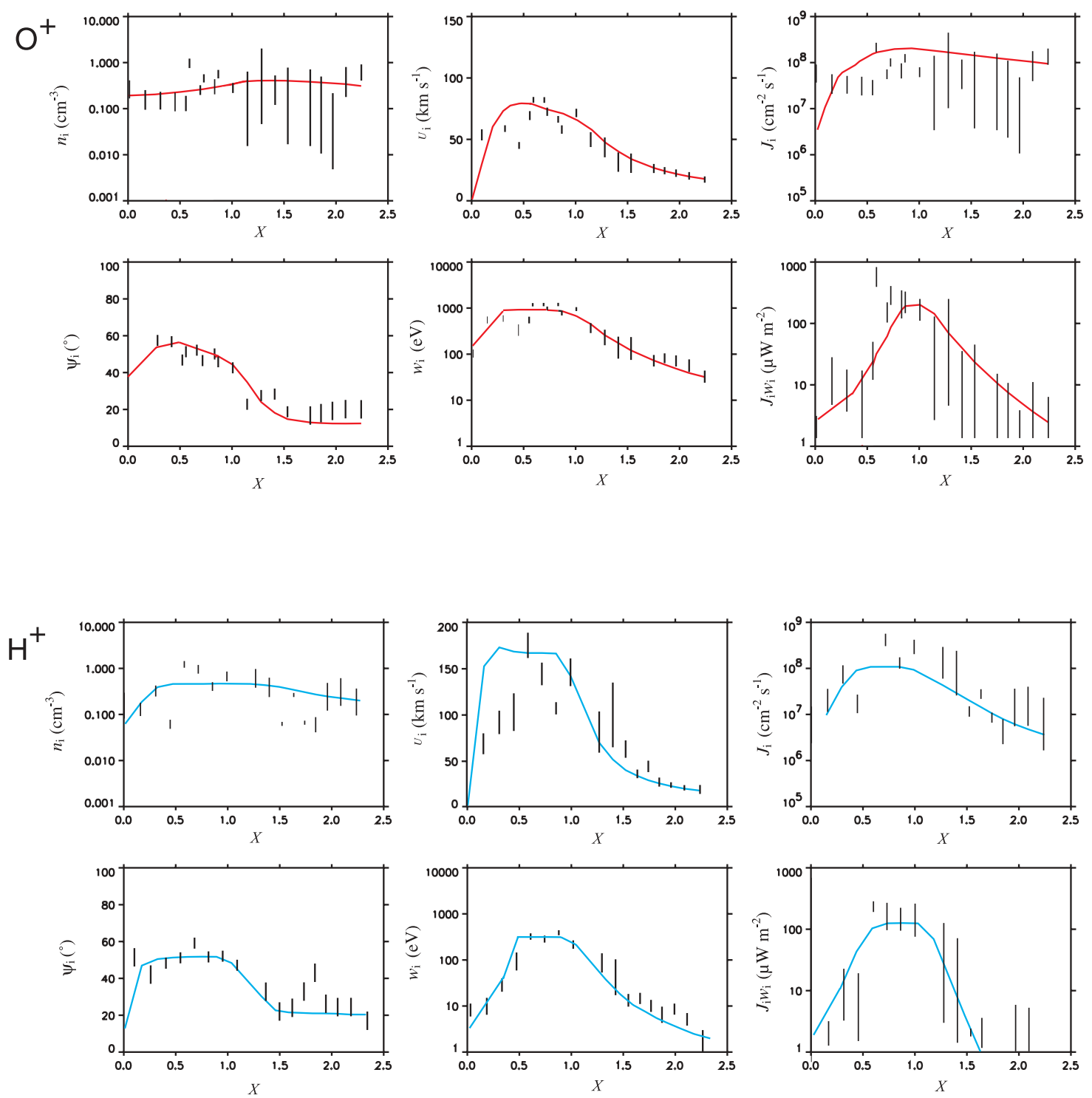

Fig. 9. Comparisons of experimental ion moments along the satellite track for event 2 with those from a numerical simulation (solid curves) for $\mathrm{O}^{+}$(top) and $\mathrm{H}^{+}$(bottom).

heating region is assumed to be uniform versus $X$ (latitude). Therefore, non-monotonic variations in the observed ion moments cannot be reproduced without introducing inhomogeneous structures versus $X$. In the same way, spatial and time variations of the ionospheric ion fluxes and density convection drift may be expected to occur. However, observations by a single satellite do not provide enough information to include these effects.

\subsection{Statistical survey}

We selected 25 cusp/cleft crossings located between 10 and 14 MLT, and at altitudes ranging from $z=1.5 R_{E}$ up to $z=3.0 R_{E}$. These cases are associated with steady IMF conditions during the transport of outflowing ions from the ionosphere up to the satellite orbit. When doing so, we expect to be in the case of a quasi-steady evolution process, where the heating region remains static and the convection patterns stationary. Here, the number of events is not sufficient for doing a detailed statistical study versus IMF. However, let us note that $80 \%$ of these events are associated with a negative $B_{z}$ component. Furthermore, we focused on cases where electrons of moderate energies $(<200 \mathrm{eV})$ are detected in the heating region so that the presence of field-aligned potential drops can be ruled out. The same procedure as described in Sects. 3.1 and 3.2 has been applied to these events. For $60 \%$ of the events, the separation between the $\mathrm{H}^{+}$conic and the component from the magnetosheath is not possible. Therefore, only $\mathrm{O}^{+}$measurements have been used as constraints to determine the parameters $\left(w_{0}, \alpha\right)$ associated with transverse ion heating.

Figures 10a and $\mathrm{b}$ show the occurrence distributions of the 
solutions $\left(w_{0}, \alpha\right)$. We note that the solutions are spread versus $\alpha$, but are still consistent with a heating profile that increases versus altitude. In Fig. 10, the solutions follow a curve $\alpha=f\left(w_{0}\right)$ that reflects the power law shape of the wave spectra used in our model. In fact, the regions associated with voids correspond to heating profiles that lead to ion energies much weaker or stronger for being observed at high altitude (see, for example, Fig. 7). After integration, we found an average spectral index $\langle\alpha\rangle=1.1 \pm 0.6$ that corresponds to a heating profile proportional to $s^{3.3 \pm 1.8}$. Furthermore, the inferred solutions $\left(w_{0}, \alpha\right)$ in the range $\alpha=1.1 \pm$ 0.6 imply spectral densities $S_{L}$ in the left-hand polarized mode at the $\mathrm{O}^{+}$gyrofrequency $f_{c} O$ varying between 0.1 and $4.0(\mathrm{mV} / \mathrm{m})^{2} \mathrm{~Hz}^{-1}$ at $z=3.0 R_{E}\left(f_{c O}=0.6 \mathrm{~Hz}\right)$, and between 0.05 and $0.40(\mathrm{mV} / \mathrm{m})^{2} \mathrm{~Hz}^{-1}$ at $z=8000 \mathrm{~km}\left(f_{c O}=\right.$ $5 \mathrm{~Hz})$.

It is here important to compare our values inferred from ion observations with those typically observed in the dayside cusp/cleft from the wave data. Using electrostatic and magnetic turbulence observations over the auroral and polar regions from Hawkeye 1, Kintner (1976) reported that the BBELF turbulence is composed of a background component with a spectral index of $1.89 \pm 0.26$ and an intense component of $2.80 \pm 0.34$. Gurnett et al. (1984) also reported an index of 2.80 but do not give an error bar, while other studies dedicated to ion transverse heating (André et al., 1990; Lund et al., 2001) give values ranging from 1.0 to 3.0. Hence, our results $(\langle\alpha\rangle=1.1 \pm 0.6)$ do not completely agree with all the previous wave power studies. Recently, statistical results have been reported for altitudes up to $10000 \mathrm{~km}$ using wave measurements from Akebono correlated with transversely heated ions (Kasahara et al., 2001), but there is no estimation of the spectral index. However, plots on the altitude distribution of the wave power at a frequency of $5 \mathrm{~Hz}$, which corresponds roughly to $f_{c O}$ at $z=8000 \mathrm{~km}$, pointed out that the wave power remains approximately constant versus altitude in the dayside cusp/cleft (Plate 5b of Kasahara et al., 2001), ranging from about $9 \times 10^{-6}$ to $2.5 \times 10^{-5}(\mathrm{~V} / \mathrm{m})^{2} \mathrm{~Hz}^{-1}$. Also using Akebono data, a statistical survey of the low-frequency $(0.2-4.0 \mathrm{~Hz})$ electric field fluctuations around the mid-altitude $(6000-10000 \mathrm{~km})$ cusp/cleft has been reported by Miyake et al. (2003). It was pointed out that the occurrence frequency of power spectral densities higher than $0.12(\mathrm{mV} / \mathrm{m})^{2} \mathrm{~Hz}^{-1}$ at $4 \mathrm{~Hz}$ is about $20 \%$, and large values up to $10(\mathrm{mV} / \mathrm{m})^{2} \mathrm{~Hz}^{-1}$ (at $4 \mathrm{~Hz}$ ) are obtained in the cusp/cleft. These latter values are from the same order up to 25 times higher than those inferred from our results in the range $\alpha=1.1 \pm 0.6$ for the component responsible of ICR heating $\left(0.05-0.40(\mathrm{mV} / \mathrm{m})^{2} \mathrm{~Hz}^{-1}\right.$ at $\left.5 \mathrm{~Hz}\right)$. For solutions associated with $\alpha>1.7$, our inferred spectral densities correspond to lower values of w 0 and are about more than 2 orders of magnitude smaller than those usually observed with Akebono. Here, it should be noted that the values observed with Akebono (Kasahara et al., 2001; Miyake et al., 2003) are surprisingly several orders of magnitude smaller than those published by Angelopoulos et al. (2001) in the cusp at $6000 \mathrm{~km}$ with Polar $\left(10^{2}-10^{4}(\mathrm{mV} / \mathrm{m})^{2} \mathrm{~Hz}^{-1}\right.$ at (a)

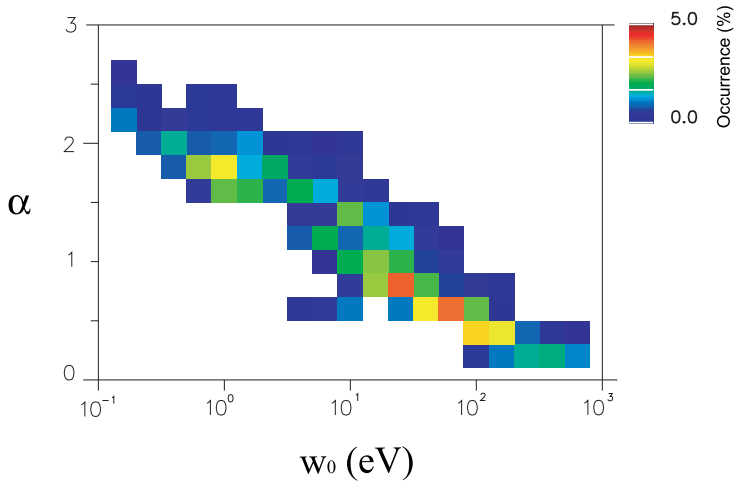

(b)

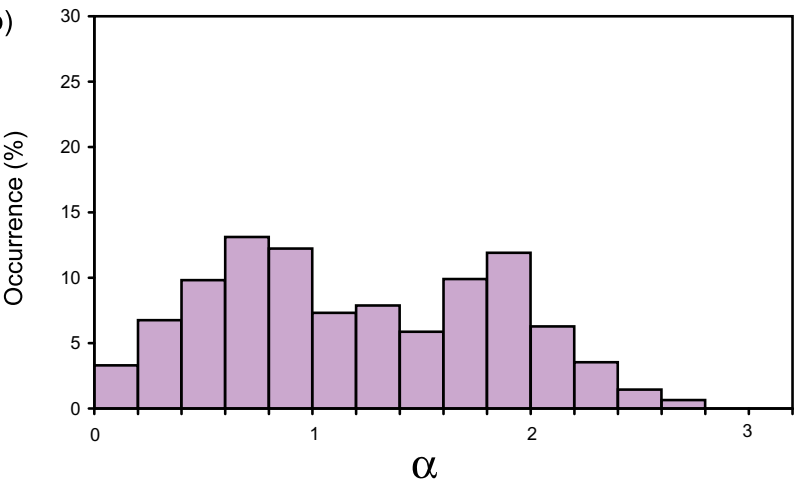

Fig. 10. (a) Occurrence distributions $P\left(w_{0}, \alpha\right)$ of the parameters associated with the heating profile versus altitude, and (b) the same distribution $P(\alpha)$ integrated over $w_{0}$.

$5 \mathrm{z}$ ). A possible explanation is that finite wavelength effects (which tend to underestimate the wave power at wavelengths equal or lower than the probe separation distance) were removed only in the work of Angelopoulos et al. (2001). These latter results suggest at least that more than one wave-mode is contained in the BBELF turbulence, and only a small fraction of the observed spectral densities may induce transverse ICR ion heating. Therefore, the most plausible way out of the dilemma related to the spectral index of the BBELF turbulence is that the mode responsible for transverse heating does not necessarily obey the same power law because it is a minor component.

In terms of global energy transfers, we may distinguish cases associated with a small index $(\alpha<1)$ from with those associated with a higher index $(\alpha>1)$. Statistically, cases where $\alpha<1$ correspond to a higher transferred power from the wave to the particles inside the heating region below the satellite. These latter cases are also associated with active geomagnetic conditions. As an example, we may apply the global conservation law of the energy density flux (see Eq. (25) of Bouhram et al., 2002a) to compare the transferred power $\left\langle P_{i}\right\rangle$ associated with events 1 and 2. Graphically, the quantity $\left\langle P_{i}\right\rangle$ is approximately equal to the area below the curve $J_{i} w_{i}(X)$ in Figs. 8 and 9. For $\mathrm{O}^{+}$ions, we find $\left\langle P_{O}\right\rangle \sim 0.8 \mu \mathrm{W} \mathrm{m}^{-2}$ and $\left\langle P_{O}\right\rangle \sim 210 \mu \mathrm{W} \mathrm{m}^{-2}$ for events 1 and 2, respectively. Qualitatively, $\alpha$ is as high as $w_{0}$ is small. Therefore, ion energies are as weak at low-altitude as 


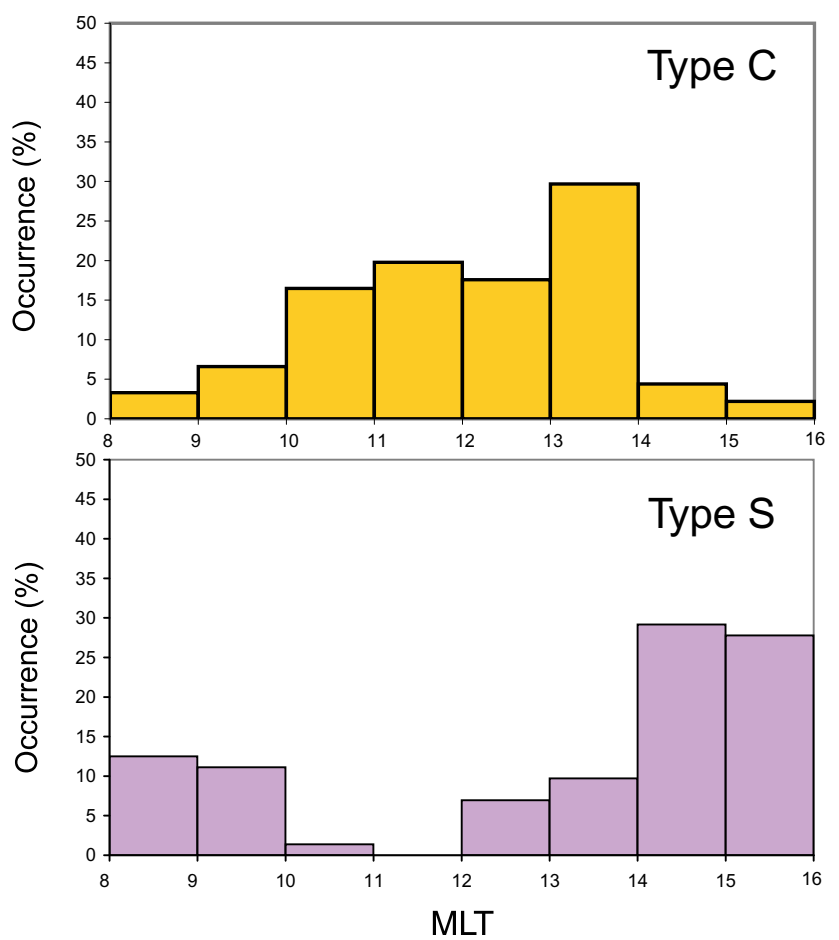

Fig. 11. Occurrence distributions of (a) type C events, and (b) type S events.

the number of ions that drift out of the heating region is high. This leads to a smaller energy density flux of ions at high altitude when $\alpha$ is high.

\section{Influence of other ion energization mechanisms}

\subsection{Occurrence distributions of field-aligned potential drops}

In Sect. 2.3, we have presented an ion energization event in the presence of field-aligned potential drops. In fact, the previous description of $\mathrm{U}$-shape potential structures was oversimplified. In reality, the potential is expected to vary in space and in time scales smaller than the typical time of flight of ionospheric ions, as recently evidenced during cases associated with multi-satellite observations (Marklund et al., 2001). In that case, our steady-state model is not applicable. Hence, if we consider a quasi-stable potential structure, the assumption of equipotential field lines, used to calculate the electric convection field at any altitude, may break down if parallel electric fields are higher than a few $\mathrm{mV} \mathrm{m}^{-1}$. In short, the resolution of the field-aligned potential structure is only possible in a self-consistent manner that is beyond the scope of the paper. However, we have studied the occurrence distributions of such structures versus MLT in the dayside cusp/cleft.

Between January 1997 and March 1998, Interball-2 crossed the dayside cusp/cleft region at all magnetic local times between 8 and $16 \mathrm{~h}$, and at altitudes ranging from 1.5 to $3 R_{E}$. Here, we have examined 224 cusp/cleft crossings by Interball-2, which have been classified into two categories. The first, named type $\mathrm{C}$, is associated with ion conics and low-energy, isotropic-like electron spectra $(<300 \mathrm{eV})$ inside the heating region. The second, named type $\mathrm{S}$, is associated with structures of field-aligned potential drops. As shown in Sect. 2.3, type $S$ events combine regions of upward and downward acceleration, but with strong upward electric fields at high altitude. Hence, high electron energies in the downward direction are naturally observed in the region of upward parallel E-field and are greater than the electron energies observed in the region of downward parallel electric fields. The 25 events selected in Sect. 3. are included in the type $\mathrm{C}$ category. The event discussed in Sect. 2.3 is included in the type $\mathrm{S}$ category. We have identified 72 type-S events and 91 type-C events. For 61 events, electron energy spectra exhibit fluxes in a broad energy range $(>300 \mathrm{eV})$ without positive $\delta f / \delta E$ slope. These later cases have been mainly observed out of the noon sector and have been discarded in the study.

Figure 11 shows the frequency of occurrence of type C and S events when grouped in one-hour MLT intervals. By far the most outstanding feature of these histogram plots is the maximum frequency of type $\mathrm{C}$ events around noon (1014 MLT), while the occurrence of type S events increases in the dusk and down sectors and is insignificant around noon. This result is consistent with statistical studies of ion beams and conics from S3-3 (Gorney et al., 1981), DE-1 (Kondo et al., 1990), Akebono (Miyake et al., 1996) and Viking (Thelin et al., 1990; Øieroset et al., 2000) satellites. These studies pointed out that beams are the main contributor to the outflow pre-noon and post-noon (cleft), while conics are dominant around noon (cusp).

\subsection{Lower-hybrid heating in the cusp}

In the cusp region, waves near and just above the lower hybrid (LH) frequency $f_{L H}$ may be generated by so-called ring distributions, resulting from the precipitating magnetosheath ions (Roth and Hudson, 1983). Since BBELF turbulence is available to pre-heat the ions up to non-thermal energies, $\mathrm{LH}$ waves may provide additional energization up to $\mathrm{keV}$ energies for $\mathrm{O}^{+}$ions at high altitude (Bouhram et al., 2002b). On the basis of a statistical survey of Freja (Norqvist et al., 1998) and FAST (Lund et al., 2000) data, there is less correlation between LH activity and ion conics than between BBELF enhancements and ion conics. In the paper of Bouhram et al. (2002c), we studied a conjunction between the Interball-2 and the FAST satellite in the cusp, where LH heating turned out to be unusually important. Here, we summarize some results presented in Bouhram et al. (2002b), and discuss the effect of LH heating on the observed distributions at the Interball-2 altitude from numerical simulations. 
Table 3. List and values of parameters used as input to a numerical simulation associated with LH heating

\begin{tabular}{lcc}
\hline \multicolumn{1}{c}{ Definition } & Notation & Value \\
\hline Residence time & $t_{D}$ & $500 \mathrm{~s}$ \\
Energization parameter & $w_{0}$ & $5 \mathrm{eV}$ \\
Spectral index & $\alpha$ & 1.5 \\
Maximum LH heating rate & $\dot{W}_{L H, M A X}$ & $1 \mathrm{eV} \mathrm{s}^{-1}$ \\
Perpendicular velocity of the maximum & $V_{r}$ & $150 \mathrm{~km} \mathrm{~s}^{-1}$ \\
$\mathrm{O}^{+}$density at $z=1000 \mathrm{~km}$ & $n_{O 0}$ & $1500 \mathrm{~cm}^{-3}$ \\
$\mathrm{O}^{+}$velocity at $z=1000 \mathrm{~km}$ & $u_{O 0}$ & $0.2 \mathrm{~km} \mathrm{~s}^{-1}$ \\
$\mathrm{O}^{+}$flux at $z=1000 \mathrm{~km}$ & $J_{O 0}$ & $3.0 \times 10^{7} \mathrm{~cm}^{-2} \mathrm{~s}^{1}$ \\
\hline
\end{tabular}

\subsubsection{Altitude and velocity dependence of LH heating}

It is possible to derive an velocity dependent expression of the ion heating rate associated with $\mathrm{LH}$ waves (Retterer et al., 1989; André et al., 1994):

$$
\dot{W}_{L H}=\left(q_{i}^{2} / 2 m_{i}\right) \times S_{L H} \times\left(V_{\perp} / V_{r}\right)^{3} /\left[1+\left(V_{\perp} / V_{r}\right)^{6}\right]
$$

where $S_{L H}$ is the spectral density around the LH frequency $f_{L H}$. The parameter $V_{r}$ denotes the phase velocity of the waves, where the heating rate is maximum, and is roughly equal to the perpendicular velocity $V \perp$, where the perpendicular gradient of the ring distribution is maximum. Figure 12 shows the evolution of the LH heating rate versus $V_{\perp}$. It turns out that only ions having velocities higher than $0.7 V_{r}$ may be in resonance with LH waves. Since $V_{r}$ is about $100-$ $200 \mathrm{~km} \mathrm{~s}^{-1}$ (Bouhram et al., 2002b), the velocity threshold is higher than typical thermal ion velocities. Therefore, a preheating mechanism, for exampl, by ion cyclotron resonance, is required so that $\mathrm{LH}$ heating is able to occur. In the case study of Bouhram et al. (2002b), it has been pointed out that the wave power contained in the BBELF turbulence is sufficient to pre-heat the ions. In that case and on the basis of Fig. 12, LH heating may be effective up to velocities of about 1.6 $V_{r}$. According to kinetic theories of LH heating (Brambilla, 1996), the mechanism induces a flat tail at high energy on the heated ion distributions.

Owing to the lack of wave measurements in a continuous altitude range, it is not possible to infer an expression of the LH heating rate as a function of altitude. However, by modelling the transport of the injected magnetosheath protons down to the ionospheric cusp along geomagnetic field lines, it has been shown that the generated LH waves may act as an efficient heating mechanism between 2000 and $10000 \mathrm{~km}$ in altitude (Bouhram et al., 2002b). Then, we may assume that a LH heating profile verifying Eq. (3) is uniform versus altitude between 2000 and $10000 \mathrm{~km}$.

\subsubsection{Effects at high altitude}

Figure 13 shows the $\mathrm{O}^{+}$velocity distribution function observed by the ION instrument in the poleward edge of the cusp at $3 R_{E}$ altitude on 17 January 1998 . Since such events

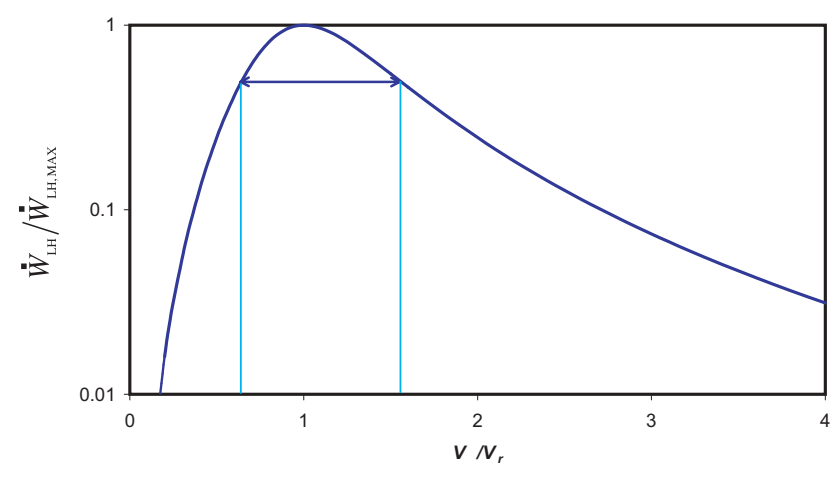

Fig. 12. LH heating rate as a function of the perpendicular velocity. The vertical lines correspond to the half-band width of the profile.

are associated with denser fluxes of injected magnetosheath protons, it is not possible to detect the ionospheric $\mathrm{H}^{+}$component inside the heating region. For comparison, we have displayed the $\mathrm{O}^{+}$velocity distribution function recorded during event 2 around 00:00 UT (see Fig. 5). The effect of LH heating is evidenced by the presence of a flat tail in the observed distribution extending at energies up to $5 \mathrm{keV}$. In Fig. 13a, the tail is observed in a direction close to the upward direction $\left(\Phi_{O} \sim 20^{\circ}\right)$, which is consistent with a LH heating occurring below the satellite altitude and followed by adiabatic folding. Here, we have computed a numerical simulation with the parameters for $\mathrm{O}^{+}$ions as listed in Table 3 . There is good agreement in Fig. 13 between the simulated distribution (red curve) in the poleward heating boundary and those measured by the ION experiment. This confirms that LH heating may contribute to strong ion energization in the polar cusp, providing a pre-heating by ion cyclotron resonance is sufficient at mid-altitudes $(2000-10000 \mathrm{~km})$.

From 27 type-C events associated with steady IMF conditions, we have found only 2 cases where LH heating may be identified from the tail of the observed high-altitude $\mathrm{O}^{+}$conics, against 25 cases where gradual ICR heating is the dominant mechanism (see Sect. 3). This agrees with previous statistical studies by the Freja (Norqvist et al., 1998) and FAST (Lund et al., 2000) satellites that suggest that LH heating is a mechanism of less importance because LH waves are poorly 

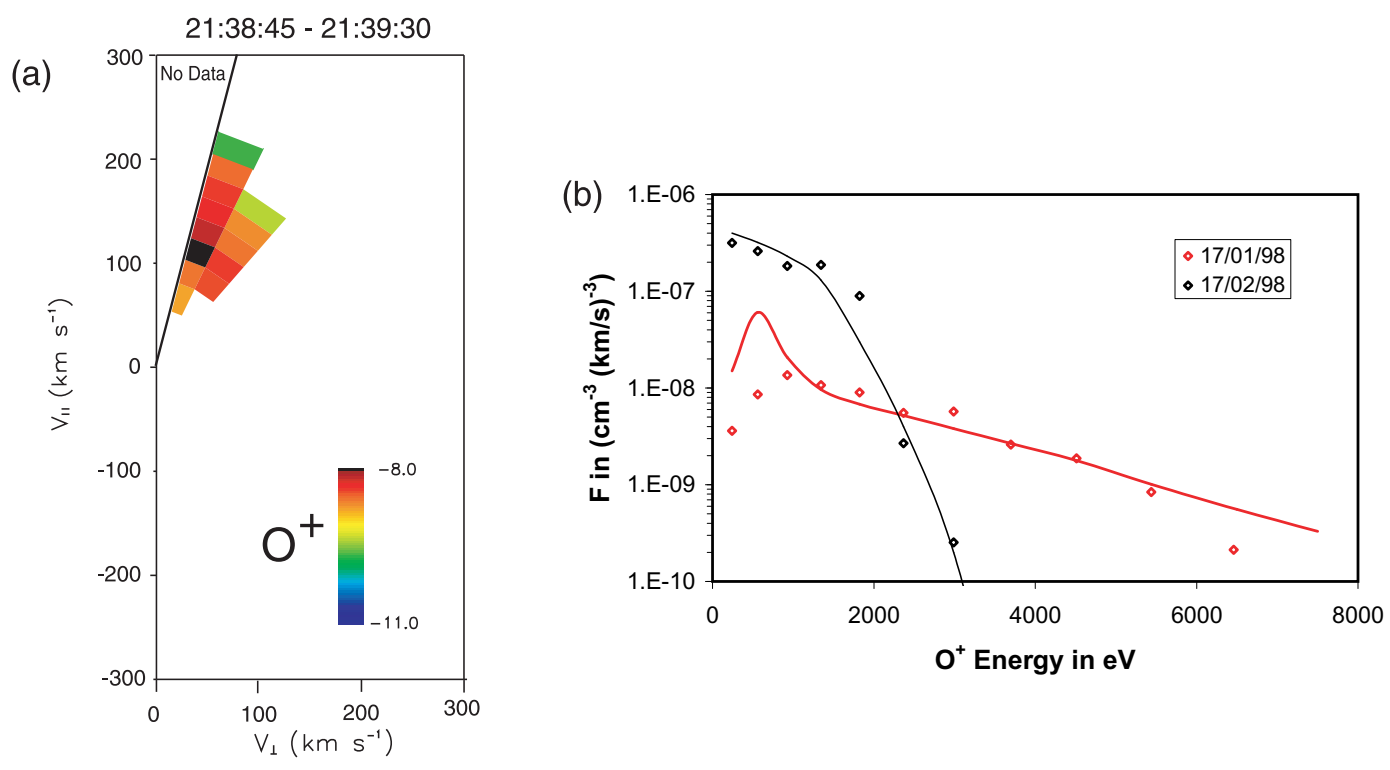

Fig. 13. (a) $\mathrm{O}^{+}$distribution function measured by the ION experiment on 17 January 1997, around 21:39 UT; (b) energy cut of the distribution in the direction of the peak flux.

correlated with ion conic observations. Regardless of these statistical results, we could expect that, since the ring distribution of magnetosheath ions is almost permanently found in the cusp, the LH waves are supposed to always be excited and able to heat ions between 2000 and $10000 \mathrm{~km}$. However, the high velocity of the ring $\left(>50 \mathrm{~km} \mathrm{~s}^{-1}\right)$ implies that $\mathrm{O}^{+}$ions have to achieve significant perpendicular energies $(>200 \mathrm{eV})$ below $10000 \mathrm{~km}$ so that $\mathrm{LH}$ can occur. When considering statistical results of ion conic energies in the cusp (see, for example, Miyake et al., 1993), such energies are likely to be uncommon below $10000 \mathrm{~km}$ and confirm that LH heating is a mechanism of less importance because of its high velocity threshold.

\section{Conclusions and future directions}

In this paper, we have studied the occurrence probability and some characteristics of different ion energization mechanisms in the dayside cusp/cleft region. According to previous statistical studies by many satellites (Gorney et al., 1981; Kondo et al., 1990; Thelin et al., 1990; Miyake et al., 1996), acceleration by field-aligned potential drops is very uncommon in the cusp (10-14 MLT), and is mainly associated with the cleft. Conversely, transverse heating by ion cyclotron resonance (ICR) seems the most plausible mechanism in the cusp, being able to explain the patterns of ion moments observed at high altitude by the Interball-2 satellite. In a few cases, ICR heating may be accompanied by LH heating in the mid-altitude cusp.

Using moments of outflowing ions measured along the satellite trajectory as constraints, we have developed a procedure in determining the altitude dependence of ion transverse heating. From 25 cusp/cleft crossings associated with steady IMF conditions, we have established that the strength of the heating by ion cyclotron resonance increases gradually as $s^{3.3 \pm 1.8}$, where s denotes the geocentric distance. We compared such dependence and the values of the wave power responsible for ICR heating with those of the BBELF spectra, as usually observed in the cusp/cleft (André et al., 1990; Angelopoulos et al., 2001; Kasahara et al., 2001). The results are consistent in the way that the wave-mode responsible for ICR heating acts as a minor component in the BBELF spectrum, since the inferred wave power values correspond to less than a few percent of those usually observed by wave experiments. We also noticed that the inferred power-law altitude dependence is also consistent with the previous statistical studies on the evolution of ion conics along the geomagnetic field lines up to $s=5 R_{E}$ (Peterson et al., 1992; Miyake et al., 1993).

These results then lead to the question of causality. On the basis of theoretical studies about current instabilities in the magnetosphere for a homogenous plasma (Kindel and Kennel, 1971), current thresholds are too high, and these mechanisms may not operate over a broad altitude range. For an inhomogenous plasma, if sheared flows are present, as it is likely in the auroral region, the thresholds are significantly lower (Gavrishchaka et al., 1999, 2000). In these latter works, the instability mechanism has been described in a local limit and has been successfully applied only to observations in the nightside upward current region by FAST at an altitude of $4000 \mathrm{~km}$. However, the ability of this mechanism to occur in the cusp and to be responsible for a gradual heating of ions over a broad altitude range (at least up to $20000 \mathrm{~km}$ ) is still an open question. According to the previous points, because electric currents are usually weaker around the cusp region than anywhere else in the auroral zone (Iijima and Potemra, 1976, 1978), we may expect that 
the source of free energy associated with transverse heating in the cusp is not local. Here, the most plausible source is Alfvén waves that are commonly propagating from the magnetopause down to the ionospheric cusp (Gurnett et al., 1984). For parallel propagation, there are two polarized modes: the right-hand circular polarized mode (RHCP), often called compressional Alfvén mode, and the left-hand circular polarized mode (LHCP), often called the shear Alfvén mode (Ichimaru, 1973). Peterson et al. (1993a, b) studied a transverse ion heating event in the cusp associated with simultaneous observations by DE- 1 at $s=4.5 R_{E}$ and Akebono at $s=2 R_{E}$, in conjunction with measurements of magnetic field perturbations from a ground station. The authors reported the conclusion that locally measured plasma particles and fields, and magnetometer data were more consistent with an interpretation of the structure as that of a standing Alfvén wave than that of a steady field-aligned current layer. During this case study, from the polarization of the waves observed at two different altitudes, it has been pointed out that a fraction of the energy of the RHCP waves propagating down to the cusp was converted into LHCP waves by reflection at low altitude. Under the presence of a parallel gradient in the magnetic field, "downcoming" RHCP waves achieve a LHCP component at the crossover frequency, and may tunnel through a frequency gap to altitudes where they contribute to ICR heating (Johnson et al., 1989). To study the idea of transverse heating by a LHCP component of propagating Alfvén waves from the magnetopause, simultaneous wave and particle measurements at several points in the midaltitude cusp and the magnetopause, such as with the Cluster mission, for example, will be needed.

Acknowledgements. The Interball Project was accomplished in the frame of contract N025-7535/94 with the Russian Space Agency (RKA). The Hyperboloid experiment was financially supported by CNES under the auspices of grants covering the period 1985 to 2002. We gratefully acknowledge D. Popescu and E. Penou from CESR for their contributions when accessing to data from the ION experiment.

Topical Editor T. Pulkkinen thanks E. Lund and another referee for their help in evaluating this paper.

\section{References}

André, M., Crew, G. B., Peterson, W. K., Persoon, A. M., Pollock, C. J., and Engebretson, M. J.: Ion heating by broadband lowfrequency waves in the cusp/cleft, J. Geophy. Res., 95, 20809 , 1990.

André, M., Norqvist, P., Vaivads, A., Eliasson, L., Norberg, O., Eriksson, A. I., and Holback, B.: Transverse ion energization and wave emissions observed by the Freja satellite, Geophys. Res. Lett., 21, 1915, 1994.

André, M. and Yau, A. W.: Theories and observations of ion energization and outflow in the high latitude magnetosphere, Space Sci. Rev., 80, 27-48, 1997.

Angelopoulos, V., Mozer, F. S., Bonnel, J., Temerin, M., Somoza, M., Peterson, W. K., Colin, H. L., and Giles, B.: Wave power studies of cusp crossings with the polar satellite, J. Geophys. Res., 106, 5987-6006, 2001.
Bonnell, J., Kintner, P. M., Wahlund, J.-E., Lynch, K., and Arnoldy, R.: Interferometric determination of broadband ELF wave phase velocity within a region of transverse auroral ion acceleration, Geophys. Res. Lett., 23, 3297, 1996.

Bouhram, M., Malingre, M., Jasperse, J. R., Dubouloz, N., and Sauvaud, J.-A.: Modelling transverse heating and outflow of ionospheric ions from the dayside cusp/cleft. 1 A parametric study, Ann. Geophysicae, this issue, 2003.

Bouhram, M.: Etude des échappements d'ions du cté jour des zones aurorales, PHD thesis, Univ. Pierre and Marie Curie, Paris, France, 2002a.

Bouhram, M., Dubouloz, N., Malingre, M., Jasperse, J. R., Pottelette, R., Senior, C., Delcourt, D., Carlson, C. W., Roth, I., Berthomier, M., and Sauvaud, J.-A.: Ion outflow and associated perpendicular heating in the cusp observed by Interball Auroral Probe and Fast Auroral Snapshot, J. Geophys. Res., 107, 10.1029/2001JA000091, 2002b

Brambilla, M.: Kinetic theory of plasma waves, Oxford Science Pub., Oxford, 1996.

Burch, J. L., Reiff, P. H., Heelis, R. A., Winningham, J. D., Hanson, W. B., Gurgiolo, C., Menietti, J. D., Hoffman, R. A., and Barfield, J. N.: Plasma injection and transport in the mid-altitude polar cusp, J. Geophys. Res., 9, 921, 1982.

Carlson, C. W., McFadden, J. P., Ergun, R. E., Temerin, M., Peria, W. J., Mozer, F. S., Klumpar, D. M., Shelley, E. G., Peterson, W. K., Möbius, E., Elphic, R., Strangeway, R., Catell, C., and Pfaff, R.: FAST observations in the downward auroral return current regions: energetic upgoing electron beams, parallel potential drops, and ion heating, Geophys. Res. Lett., 25, $2017-$ 2020, 1998.

Chang, T., Crew, G. B., Hershkowitz, N., Jasperse, J. R., Retterer, J. M., and Winningham, J. D.: Transverse acceleration of oxygen ions by electromagnetic ion cyclotron resonance with broadband left-hand-polarized waves, Geophys. Res. Lett., 13, 636639, 1986.

Crew, G. B., Chang, T., Retterer, J. M., Peterson, W. K., Gurnett, D. A., and Huff, R. L.: Ion cyclotron resonance heated conics: theory and observations, J. Geophys. Res., 95, 3959, 1990.

Dubouloz, N., Berthelier, J.-J., Malingre, M., Girard, L., Galperin, Y., Covinhes, J., Chugunin, D., Godefroy, M., Gogly, G., Guérin, C., Illiano, J.-M., Kossa, P., Leblanc, F., Legoff, F., Mularchik, T., Paris, J., Stzepourginski, W. Vivat, F., and Zinin, L.: Thermal ion measurements on board Interball Auroral Probe by the Hyperboloid experiment, Ann. Geophysicae, 16, 1070-1086, 1998.

Erlandson, R. E., Zanetti, L. J., Acuna, M. H., Eriksson, A., Eliasson, L., Boehm, M. H., and Blomberg, L.: Freja observations of electromagnetic ion cyclotron (ELF) waves and transverse oxygen acceleration on auroral field lines, Geophys. Res. Lett., 21, 1855, 1994.

Gavrishchaka, V. V., Ganguli, S. B., and Ganguli, G. I. : Electrostatic oscillations due to filamentary structures in the magneticfield-aligned flow: The ion acoustic branch, J. Geophys. Res., 104, 12 683, 1999.

Gavrishchaka, V. V., Ganguli, G. I., Scales, W. A., Slinker, S. P., Chaston, C. C., McFadden, J. P., Ergun, R. E., and Carlson, C. W.: Multiscale coherent structures and broadband waves due to parallel inhomogeneous flows, Phys. Rev. Lett., 85, 4285, 2000.

Gorney, D. J., Clarke,A., Croley, D. R., Fennell, J., Luhmann, J., and Mizera, P.: The distribution of ion beams and conics below 8000 km, J. Geophys. Res., 86, 83, 1981.

Gorney, D. J., Chiu, Y. T., and Croley, Jr., D. R.: Trapping of ion 
conics by downward parallel electric fields, J. Geophys. Res., 90, 4205, 1985.

Gurnett, D. A., Huff, R. L., Menietti, J. D., Burch, J. L., Winningham, J. D., and Shawhan, S. D.: Correlated low-frequency electric and magnetic noise along the auroral field lines, J. Geophys. Res., 89, 8971-8985, 1984.

Horwitz, J. L.: Velocity filter mechanism for ion bowl distributions (Bimodal conics), J. Geophys. Res., 91, 4513, 1986.

Ichimaru, S.: Basic principles of plasma physics: A statistical approach, p. 90, W. A. Benjamin, Reading, Mass., 1973.

Iijima, T. and Potemra, T. A.: Field-aligned currents in the dayside cusp observed by Triad, J. Geophys. Res., 81, 5971, 1976.

Iijima, T. and Potemra, T. A. Large scale characteristics of fieldaligned currents associated with substorms, J. Geophys. Res., 83, 599, 1978.

Jasperse, J. R.: Ion heating, electron acceleration and the selfconsistent parallel E-field in downward auroral current regions, Geohys. Res. Lett., 25, 3485-3488, 1998.

Johnson, J. R., Chang, T., Crew, G. B., and André, M.: Equatorially generated ULF waves as a source for the turbulence associated with ion conics, Geophys. Res. Lett., 16, 1469, 1989.

Kasahara, Y., Hosoda, T., Mukai, T., Watanabe, S., Kimura, I., Kojima, H., and Niitsu, R.: ELF/VLF waves correlated with transversely accelerated ions in the auroral region observed by Akebono, J. Geophys. Res., 106, 21 123-21 136, 2001.

Kindel, J. M. and Kennel, C. F.: Topside current instabilities, J. Geophys. Res., 76, 3055, 1971.

Kintner, P. M.: Observations of velocity shear driven plasma turbulence, J. Geophys. Res. , 81, 5114-5122, 1976.

Kondo, T., Whalen, B. A., Yau, A. W., and Peterson, W. K.: Statistical analysis of upflowing ion beam and conic distributions at DE 1 altitudes, J. Geophys. Res., 95, 12 091, 1990.

Klumpar, D. M., Peterson, W. K., and Shelley, E. G.: Direct evidence for two-stage (bimodal) acceleration of ionospheric ions, J. Geophys. Res., 89, $10779,1984$.

Knudsen, D. J., Whalen, B. A., Abe, T., and Yau, A.: Temporal evolution and spatial dispersion of ion conics: evidence of a polar cusp heating wall, in: Solar System Plasmas in Space and Time, Geophys. Monogr. Ser., vol. 84, edited by Burch, J. L. and Waite, Jr., J. H., 163-169, AGU, Washington D.C., 1994.

Lockwood, M., Chandler, M. O., Horwitz, J. L., Waite, Jr., J. H., Moore, T. E., and Chappell, C. R.: The cleft ion fountain, J. Geophys. Res., 90, 9736, 1985.

Lund, E. J., Möbius, E., Carlson, C. W., Ergun, R. E., Kistler, L. M., Klecker, B., Klumpar, D. M., McFadden, J. P., Popecki, M. A., Strangeway, R. J., and Tung, Y. K.: Transverse ion acceleration mechanism in the aurora at solar minimum: occurrence distributions, J. Atmos. Terr. Phys., 62, 467-475, 2000.

Lund, E. J., E. Möbius, Lynch, K. A., Klumpar, D. M., Peterson, W. K., Ergun, R. E., and Carlson, C. W.: On the mass dependence of transverse ion acceleration by broadband extremely low frequency waves, Phys. Chem. Earth, 26, 161-163, 2001.

Marklund, G. T., Karlsson, T., and Clemmons, J.: On low-altitude particle acceleration and intense electric field and their relationship to black aurora, J. Geophys. Res., 102, 17 509, 1997.

Marklund, G. T., Ivchenko, N., Karlsson, T., Fazakerley, A., Dunlop, M., Lindqvist, P.-A., Buchert, S., Owen, C., Taylor, M., Vaivads, A., Carter, P., André, M., and Balogh, A.: Temporal evolution of the electric field accelerating electrons away from the auroral ionosphere, Nature, 414, 724-727, 2001.

Miyake, W., Mukai, T., and Kaya, N.: On the evolution of ion conics along the field line from EXOS-D observations, J. Geophys.
Res., 98, 11 127, 1993.

Miyake, W., Mukai, T., and Kaya, N.: On the origins of the upward shift of elevated (bimodal) ion conics in velocity space, $\mathrm{J}$. Geophys. Res., 101, 26 961, 1996.

Miyake, W., Matsuoka, A., and Hirano, Y.: A statistical survey of low-frequency electric field fluctuations around the dayside cusp/cleft region, J. Geophys. Res., 108(A1), 1008, 10.1029/2002JA009265, 2003.

Moore, T. E., Lundin, R., Alcaydé, D., André, M., Ganguli, S. B., Temerin, M., and Yau, A.: Source processes in the high-altitude ionosphere, Space Sci. Rev., 88, 7-84, 1999.

Newell, P. T. and Meng, C.-I.: The cusp and the cleft/boundary layer: Low-altitude identification and statistical local time variation, J. Geophys. Res., 93, 14 549-14 556, 1988.

Norqvist, P., André, M., Eliasson, L., Eriksson, A. I., Blomberg, L., Lühr, H., and Clemmons, J. H.: Ion cyclotron heating in the dayside magnetosphere, J. Geophys. Res., 101, 13 179, 1996.

Norqvist, P., André, M., and Tyrland, M.: A statistical study of ion energization mechanisms in the auroral region, J. Geophys. Res. 103, 23 459-23 473, 1998.

Øieroset, M., Yamauchi, M., Liszka, L., and Christon, S. P.: Energetic ion outflow from the dayside ionosphere and its relationship to the interplanetary magnetic field and substorm activity, J. Atmos. Terr. Phys., 62, 485-493, 2000.

Papitashvili, V. O. and Rich, F. J.: High-latitude ionospheric convection models derived from Defense Meteorogical Satellite Program ion drift observations and parametrized by the interplanetary magnetic field strength and direction, J. Geophys. Res., 107(A8), 10.1029/2001JA000264, 2002.

Peterson, W. K., Collin, H. L., Doherty, M. F., and Bjorklund, C. $\mathrm{M} .: \mathrm{O}^{+}$and $\mathrm{He}^{+}$restricted and extended (bi-modal) ion conic distributions, Geophys. Res. Lett., 19, 1439-1442, 1992.

Peterson, W. K., Yau, A. W., and Whalen, B. A.: Simultaneous observations of $\mathrm{H}^{+}$and $\mathrm{O}^{+}$ions at two altitudes by the Akebono and Dynamics Explorer 1 satellites, J. Geophys. Res., 98, 11 177, 1993a.

Peterson, W. K., Abe, T., André, M., Engebretson, M. J., Fukunishi, H., Hayakawa, H., Matsuoka, A., Mukai, T., Persoon, A. M., Retterer, J. M., Robinson, R. M., Sugiura, M., Tsuruda, K., Wallis, D. D., and Yau, A. W.: Observations of a transverse magnetic field perturbation at two altitudes on the equatoward edge of the magnetospheric cusp, J. Geophys. Res., 98, 21 463, 1993 b.

Retterer, J. M., Chang, T., Crew, G. B., Jasperse, J. R., and Winningham, J. D.: Monte Carlo modeling of ionospheric oxygen acceleration by cyclotron resonance with broad-band electromagnetic turbulence, Phys. Rev. Lett., 59, 148-151, 1987.

Retterer, J. M., Chang, T., and Jasperse, J. R.: Particle acceleration by intense auroral VLF turbulence, in: Physics of Space Plasmas, edited by Chang, T., Crew, G. B., and Jasperse, J. R., 119, Sci. Publishers, Cambridge, Angleterre, 1989.

Roth, I. and Hudson, M. K.: Particle simulations of electrostatic emissions near the lower hybrid frequency, J. Geophys. Res., 88, 483, 1983.

Ruohoniemi, J. M. and Greenwald, R. A.: Statistical patterns of high-latitude convection obtained from Goose Bay HF radar observations, J. Geophys. Res., 101, 21 473, 1996.

Sauvaud, J.-A., Barthe, H., Aoustin, C., Thocaven, J.-J., Rouzaud, J., Penou, E., Popescu, D., Kovrazhkin, R. A., and Afanasiev, K. G.: The ion experiment onboard the Interball-Aurora satellite: initial results on velocity-dispersed structures in the cleft and inside the auroral oval, Ann. Geophysicae, 16, 1056-1069, 1998. 
Shelley, E. G., Johnson, R. G., and Sharp, R. D.: Satellite observations of energetic heavy ions during a geomagnetic storm, J. Geophys. Res., 77, 6104, 1972.

Stasiewicz, K., Khotyaintsev, Y., Berthomier, M., and Wahlund, J.E.: Identification of a widespread turbulence of dispersive Alfvén waves, Geophys. Res. Lett., 27, 173, 2000.

Su, Y.-J., Horwitz, J. L., Wilson, G. R., Richards, P. G., Brown, D. G., and Ho, C. W.: Self-consistent simulation of the photoelectron-driven polar wind from $120 \mathrm{~km}$ to $9 R_{E}$ altitude, J. Geophys. Res., 103, 2279-2296, 1998.

Thelin, B., Aparicio, B., and Lundin, R.: Observations of upflow- ing ionospheric ions in the mid-altitude cusp/cleft region with the Viking satellite, J. Geophys. Res., 95, 5931-5939, 1990.

Wahlund, J.-E., Eriksson, A. I., Holback, B., Boehm, M. H., Bonnel, J., Kintner, P. M., Seyler, C. E., Clemmons, J. H., Eliasson, L., Knudsen, D. J., Norqvist, P., and Zanetti, L. J.: Broadband ELF plasma emission during auroral energization 1. Slow ion acoustic waves, J. Geophys. Res., 103, 4343, 1998.

Weimer, D. R.: Models of high-latitude electric potentials derived with a last error fit of spherical harmonic coefficients, J. Geophys. Res., 100, 19595-19607, 1995. 